\title{
Fatores Pessoais que Motivam a Doação de Dinheiro e/ou Bens para Fins Filantrópicos
}

\author{
Personal Factors Motivating that Motivate the Donation of Money and/or Goods Donation for Philanthropic Purposes
}

Factores personales que motivan la donación de dinero y / o bienes para fines filantrópicos

Rozelia Laurett

Doutoranda em Administração pela Universidade da Beira Interior - Portugal. http://lattes.cnpq.br/3255885019637534 rozelialaurett@gmail.com

Emerson Wagner Mainardes

Doutorado em Administração pela Universidade da Beira Interior - Portugal. Professor Fundação Instituto Capixaba de Pesq. em Contabilidade, Economia e Finanças, FUCAPE, Brasil. http://lattes.cnpq.br/9828374447862752

emerson@fucape.br

Resumo: Esta pesquisa teve como objetivo geral identificar os fatores pessoais que motivam os brasileiros a doarem dinheiro e/ou bens. Para alcançar tal objetivo foi realizada uma pesquisa quantitativa com corte transversal. Inicialmente foram identificadas na literatura 58 características pessoais, que tendem a motivar o comportamento de doação de dinheiro e/ou bens. Estas variáveis foram convertidas em afirmações e posteriormente, estruturadas em um questionário com uma escala de Likert de 5 pontos. Este questionário foi aplicado junto a 1.073 doadores brasileiros que afirmaram realizar a doação de dinheiro e/ou bens. Após coletados os dados, foi realizada a análise fatorial. $\mathrm{O}$ agrupamento das variáveis na análise fatorial resultou em 10 fatores de características pessoais (Conformidade Social, Aspectos Sociodemográficos, Necessidade Prazer em Ajudar, Aspectos Econômicos, Comprometimento com o Próximo, Benefícios Psicológicos, Auto Reflexão, Contribuição à Sociedade, Situação Pessoal e Humor e Hábito). Tal análise favoreceu a identificação de dimensões subjacentes das características pessoais que tendem a motivar a doação de dinheiro e/ou bens. Palavras-chave: Comportamento do doador. Características pessoais. Doação de dinheiro e/ou bens. Motivação para doação. Doação para organizações filantrópicas.
Abstract: The main objective of this research was to identify the personal factors that motivate Brazilians to donate money and/or goods. To achieve this objective a quantitative cross sectional study was carried out. Initially 58 personal characteristics that lean to motivate the donation behavior of money and/or goods were identified in literature. These variables were converted into statements and structured into a questionnaire with a Likert scale of 5 points. This questionnaire was applied to 1073 Brazilian donors who stated money and/or goods donation. Once the data were achieved a factorial analysis was performed. The variable grouping on the exploratory factor analysis resulted in 10 factors of personal characteristics (Personal Behavior Sociodemographic Aspects, Need and Pleasure in Helping, Economic Aspects, Commitment to Others, Psychological Benefits, Self Reflection, Contribution to Society, Personal Situation, Willingness to Help). This analysis promoted the identification of underlying dimensions of personal characteristics that tend to motivate the money and/or goods donation.

Keywords: Donor behavior. Personal characteristics. Money and/or goods donation. Motivation for donation. Philanthropic donation.
Resumen: Esta investigación tuvo como objetivo general identificar los factores personales que motivan a los brasileños a donar dinero y / o bienes. Para alcanzar tal objetivo se realizó una investigación cuantitativa con corte transversal. Inicialmente se identificaron en la literatura 58 características personales, que tienden a motivar el comportamiento de donación de dinero y / o bienes. Estas variables se convirtieron en afirmaciones y posteriormente se estructuraron en un cuestionario con una escala de Likert de 5 puntos. Este cuestionario fue aplicado junto a 1.073 donantes brasileños que afirmaron realizar la donación de dinero y / o bienes. Después de recolectados los datos, se realizó el análisis factorial. La agrupación de las variables en el análisis factorial resultó en 10 factores de características personales (Conformidad Social, Aspectos Sociodemográficos, Necesidad y Placer en Ayudar, Aspectos Económicos, Compromiso con el Siguiente, Beneficios Psicológicos, Auto Reflexión, Contribución a la Sociedad, Situación Personal y Humor y hábito). Este análisis favoreció la identificación de dimensiones subyacentes de las características personales que tienden a motivar la donación de dinero y / o bienes.

Palabras clave: Comportamiento del donante. Características personales. Donación de dinero y / o bienes. Motivación para la donación. Donación para organizaciones filantrópicas.

Texto completo em português: http://www.apgs.ufv.br

Full text in Portuguese: http://www.apgs.ufv.br

\section{Introdução}

O setor filantrópico vem crescendo e desempenhando um papel cada vez mais importante na sociedade (Gottesman, Reagan \& Dodds, 2014), e as organizações que fazem parte deste setor possuem como significativa fonte de receita, as doações (OttoniWilhelm, 2010). Estas doações mostram-se como um importante componente da atividade econômica de diversos países e apresentam um impacto considerável na economia, contribuindo para a continuidade e manutenção de uma grande diversidade de organizações de caridade (Mathur, 2013; Gottesman, et al., 2014).

Um exemplo é os Estados Unidos da América, onde, em 2012, os indivíduos americanos doaram mais de 200 milhões de dólares para causas de caridade (Lee, Winterich \& Ross, 2014). Este alto comprometimento dos americanos junto ao setor sem fins lucrativos, pode ser, segundo Gottesman et al. (2014), devido ao fato deste setor desempenhar um papel significativo na vida social e econômica dos americanos, ao oferecer à população, serviços de educação, saúde humana, animal e ambiental, segurança pública, arte e cultura.

Neste contexto, o aumento do número de organizações de caridade e a sua importância social e econômica, gera a necessidade de ampliação da arrecadação de receitas por meio de doações. Consequentemente, a disputa por doadores também torna-se mais competitiva. Por isso, de acordo com Winterich e 
Zhang (2014), compreender as motivações que favorecem o comportamento de doação, tornou-se um tema relevante para pesquisadores e profissionais da área a nível mundial (Grace \& Griffin, 2006; Borgonovi, 2008; Grace \& Griffin, 2009; Opoku, 2013; Barcellos, 2014; Du, Qian \& Feng, 2014).

Dentre estas motivações, os pesquisadores identificaram que os indivíduos podem realizar doações motivadas pelas características do próprio doador (Bekkers \& Wiepking, 2006, 2007; Bekkers, 2010; Choi \& Dinitto, 2012; Mittelman, Rojas-Méndez, 2013; Casale \& Baumann, 2013; Lee, Winterich \& Ross, 2014) ou serem motivados por influências externas (Bekkers \& Wiepking, 2007; Grace \& Griffin, 2009; Mainardes et al., 2015).

Assim, pôde-se perceber pelas pesquisas já realizadas que existem diversas variáveis relativas às características pessoais e fatores externos que motivam o doador e estão dispersas na literatura, e poucos estudos buscaram sistematizar e agrupar estas variáveis em fatores (BEKKERS \& WIEPKING, 2007, 2011B; MAINARDES et al., 2015). Bekkers e Wiepking (2007, 2011b) estudaram em conjunto os fatores internos e externos, mas não testaram empiricamente estes fatores. Já Mainardes et al. (2015) validaram, em pesquisa qualitativa, fatores internos e externos, porém não avançaram para uma confirmação estatística dos fatores, sugerindo isso como estudo futuro. Complementarmente, verificou-se que estes pesquisadores não realizaram estudos específicos para compreender somente os fatores internos e/ou externos que motivam a doação de dinheiro e/ou bens.

Neste sentido, este estudo visou responder o seguinte problema de pesquisa: Quais são as características de uma pessoa que motivam as doações de dinheiro e/ou bens? Para responder a esta questão, teve-se como objetivo geral identificar os fatores pessoais que motivam os doadores brasileiros a doarem dinheiro e/ou bens por meio da realização de um estudo de cunho exploratório.

Segundo os relatórios do World Giving Index (Charities Aid Foundation, 2012; 2014), o Brasil, em 2012, encontrava-se no ranking mundial em octogésimo terceiro lugar em relação à doação geral (dinheiro, ajuda a outros e tempo) e, em 2014, foi para a nonagésima colocação. Em relação à doação de dinheiro especificamente, o Brasil estava em sexagésimo oitavo em 2012, mas em 2014 passou para septuagésimo primeiro lugar no ranking mundial de doação de dinheiro. Logo, percebe-se que o Brasil, neste período, sofreu uma queda significativa no ranking de países que mais doam, tanto em relação à doação geral, quanto à doação de dinheiro.

Além disso, o atual cenário econômico negativo no qual o país encontra-se pode influenciar o processo de captação e manutenção das doações, pois, segundo Cronin-Gilmore, Bates e Brown (2014), a situação econômica de um país pode afetar os indivíduos e as instituições de caridade que dependem de doações. Neste contexto, estudar o comportamento do doador torna-se ainda mais relevante, levando-se em consideração a queda do ranking de doações do Brasil e o atual cenário econômico do país.
Também buscou-se compreender neste estudo apenas o comportamento do doador de dinheiro e/ou bens, pois foram identificados poucos estudos que tratam deste doador específico (Barcellos, 2014), tanto no Brasil, como em outros países. Os estudos anteriores identificados tratavam de doação de sangue (Zago, 2010), órgãos e tecidos (Teixeira, Gonçalves \& Silva, 2012), tempo e dinheiro (Wymer \& Samu, 2002; Bekkers, 2010; Agostinho \& Paço, 2012).

Complementarmente, na prática, o entendimento, por parte das organizações de caridade das características individuais que levam uma pessoa a realizar doações, pode auxiliar os seus gestores no recrutamento de novos doadores e retenção dos atuais (Choi \& Dinitto, 2012) e possibilitar a construção de relacionamentos de longo prazo com os seus doadores (Merchant, Ford \& Sargeant, 2010). Pode também apoiar os gestores na melhoria das ações de marketing junto aos seus doadores (Opoku, 2013; Cronin-Gilmore, Bates \& Brown, 2014; Lee, Et Al., 2014).

Para Kim (2014), da mesma forma como o estudo do comportamento do consumidor visa estudar e entender o comportamento de compra de produtos e serviços, o estudo do comportamento do doador visa entender os motivos que levam indivíduos a doarem dinheiro, bens, tempo e outros recursos. Assim, quanto mais conhecimento se tem sobre o comportamento dos doadores, mais claras e coerentes podem ser as estratégias de captação de recursos e a manutenção dos doadores.

Como contribuição acadêmica, esta pesquisa deu continuidade aos estudos relativos ao tema doação, às organizações filantrópicas e ao comportamento do doador brasileiro de dinheiro e/ou bens. No contexto brasileiro, foram identificados poucos estudos que buscam compreender o comportamento do doador de dinheiro e/ou bens. Ainda para a teoria, este trabalho identificou na literatura 58 características pessoais que motivam a doação de dinheiro e/ou bens e realizou o agrupamento inicial destas variáveis em 10 fatores que tendem a explicar o comportamento do doador brasileiro de dinheiro e/ou bens. Este agrupamento pode ser considerado inédito na literatura científica brasileira. Outra contribuição deste estudo foi pesquisar apenas os aspectos do indivíduo e testá-los empiricamente, como recomendado em estudos anteriores (Bekkers \& Wiepking, 2007; 2011b; Mainardes et al., 2015).

Para Osili, Hirt e Raghavan (2011), a importância de se estudar este tema pode ser devido ao fato das doações para a caridade desempenharem um papel importante no fornecimento de serviços sociais. Neste contexto, compreender o comportamento dos doadores tende a ser relevante para a continuidade das organizações de caridade. Além disso, muitas organizações de caridade estão sendo pressionadas por uma crescente demanda por seus serviços, aumento da concorrência, escassez de recursos financeiros e redução do apoio do governo, o que leva a necessidade destas organizações cada vez mais compreenderem o comportamento do doador para arrecadar recursos (Mittelman \& Rojas-Méndez, 2013).

\section{Comportamento do Doador}


Nas últimas décadas, o interesse em compreender como e por que doações são efetuadas, tanto por indivíduos, como por organizações privadas, vem despertando o empenho de diversos pesquisadores de diversas áreas, tais como: economia, finanças, estatística, religião, sociologia, psicologia, marketing, recursos humanos e administração (Yöruk, 2013; Borgonovi, 2008; Whitehead lii, 2014; Ottoni-Wilhelm, 2010; Choi \& Dinitto, 2012; Marx; Carter, 2014; Wymer \& Samu, 2002; Grace \& Griffin, 2006; Bekkers \& Wiepking, 2011b). A relevância deste tema para a literatura acadêmica também pode ser percebida ao pesquisar no Googlescholar a palavra-chave "charitable giving", ou seja, "doações de caridade". Esta base de dados ao ser pesquisado em 18/08/2015 forneceu aproximadamente 247 mil resultados.

Neste sentido, diversos estudos vêm sendo desenvolvidos a fim de entender o comportamento de doação, como o de Bekkers e Wiepking (2007), que buscou compreender, a partir de uma análise da literatura de 50 anos (1955-2005) de teorias e pesquisas sobre doações de caridade em diversas áreas (conforme já citado no início deste tópico) a fim de compreender o que leva os doadores a se dedicarem e se envolverem em atos de caridade. Nesta pesquisa, os autores identificaram sete mecanismos que impulsionam a doação: (1) solicitação; (2) consciência da necessidade; (3) os custos; (4) a reputação; (5) os benefícios psicológicos; (6) mudar o mundo; e a (7) confiança. Os autores consideraram que, a partir destes achados, é possível orientar pesquisadores e profissionais do terceiro setor sobre os fatores que determinam a doação.

Em outra pesquisa, Bekkers e Wiepking (2011b) realizaram uma revisão de literatura de 500 artigos acadêmicos a fim de identificar os motivadores da doação, e evidenciaram oito mecanismos que explicam este comportamento: (1) a consciência da necessidade; (2) a solicitação; (3) os custos e benefícios; (4) o altruísmo; (5) a reputação; (6) os benefícios psicológicos; (7) os valores; e (8) a eficácia. Já Mainardes et al. (2015) realizaram uma revisão da literatura no qual identificaram 103 variáveis que motivam o ato da doação e agruparam estas variáveis por similaridade e propuseram um modelo de comportamento de doação. Este modelo foi composto por nove fatores, quatro relativos às características pessoais dos indivíduos e 5 referentes aos motivadores externos de doação. Este modelo foi testado por meio de entrevistas junto a 22 doadores frequentes de dinheiro e/ou bens. Como resultado do estudo, foi evidenciado que o modelo proposto pelos autores (Mainardes et al. 2015) tende a explicar o comportamento do doador de dinheiro e/ou bens.

Desta forma, na parte seguinte, este trabalho visou reunir as variáveis individuais identificadas em pesquisas anteriores e verificar quais são as que, segundo os doadores, podem contribuir com o comportamento do doador. A seguir, é apresentada uma revisão da literatura sobre as variáveis individuais que motivam a doação de dinheiro e/ou bens.

\subsection{Características pessoais que motivam a doação de dinheiro} e/ou bens
Vários estudos, listados na sequência, analisaram o comportamento do doador a partir das características demográficas. A variável idade é conhecida como um importante motivador no processo de doação, onde os resultados das pesquisas identificaram que pessoas com mais idade tendem a doar mais (Sargeant, 1999; Bennett, 2003; Marx \& Carter, 2014; Gottesman, et al., 2014; Curtis, Evans \& Cnaan, 2015). O estudo de Cronin-Gilmore, Bates e Brown (2014) identificou que mulheres doam mais que homens. Porém, Wiepking e Bekkers (2012) identificaram que os homens tendem a doar valores mais elevados dos que as mulheres. Já o nível de escolaridade, estudada por Choi e Dinitto (2012), demonstra que indivíduos com grau de escolaridade mais elevado tendem a doar mais. Além disso, a renda também tem importante ligação com o ato da doação (Choi \& Dinitto, 2012; Casale \& Baumann, 2013).

Já Du et al. (2014), ao analisar o estado civil do indivíduo, identificaram que pessoas casadas doam mais. $O$ fato de o doador ter filhos também foi identificado como uma variável motivadora de doação. Quanto mais filhos, mais doações (Osili, Hirt \& Raghavan, 2011). Outras variáveis como morar em zona rural ou urbana (Bekkers \& Wiepking, 2006), o tamanho da cidade onde o indivíduo mora (Bekkers \& Wiepking, 2007), a classe social e a origem étnica (Wiepking \& Breeze, 2012) e se o indivíduo goza de boa saúde (Gottesman, et al., 2014), foram consideradas como variáveis relevantes para compreender o comportamento de doação de dinheiro e/ou bens. A variável religião também recebe destaque quando o assunto é caridade. Segundo Casale e Baumann (2013), a religião tem uma forte ligação com a caridade, e indivíduos que praticam uma religião tendem a estar mais envolvidos com atos de doação, algo também identificado por Bekkers e Wiepking (2006).

Outra variável presente na literatura, refere-se aos indivíduos que estão seguros financeiramente, e estes tendem a doar mais (Wiepking \& Breeze, 2012). Isto parece acontecer também com os que estão empregados (Bekkers \& Wiepking, 2007) e os que possuem casa própria (Bekkers \& Wiepking, 2006). O estudo de Du et al. (2014) identificou que possuir casa própria influencia significativamente em caso do indivíduo realizar doações para a religião. Em outros estudos (Amato, 1985; Sargeant, 1999; Bekkers, 2010), os pesquisadores identificaram que pessoas que tem profissão de ajuda, como médicos, enfermeiros e assistentes sociais, tendem a ajudar mais, devido ao fato de lidarem com problemas sociais no seu dia a dia.

Indivíduos que se consideram responsáveis socialmente também contribuem mais com a caridade (Mathur, 2013). Muitos também se envolvem em atividades de doação pelo desejo de criarem um mundo mais justo (Bekkers \& Wiepking, 2011b). Pesquisadores como Bekkers e Wiepking (2011b) apontaram que as pessoas que possuem maior status social doam mais. Já Du, Qian e Feng (2014) identificaram que as pessoas realizam doações porque buscam uma reputação social, bem como reconhecimento público (Bekkers \& Schuyt, 2008) e/ou prestígio perante a sociedade (Mittelman \& Rojas-Méndez, 2013). 
Os sentimentos dos indivíduos também podem motivar doações, como a "alegria de doar" (Anik et al. 2009; Bekkers \& Wiepking, 2010). Outros estudos têm fornecido evidências de que os sentimentos altruístas são determinantes na decisão de doar (Bekkers \& Wiepking, 2011b). Outros pesquisadores buscaram compreender diferentes motivos que podem levar um indivíduo a doar e identificaram o altruísmo, a empatia, a simpatia, o hedonismo, a compaixão, a generosidade, o desejo de fazer a diferença e de ajudar a sociedade (Sargent, 1999; Benett, 2003; Sargeant \& Woodliffe, 2007; Germain et al., 2007; Lee \& Chang, 2007; Michel \& Reunier, 2012; Mittelman \& Rojas-Méndez, 2013; Mathur, 2013).

Indivíduos também podem ser motivados a doar quando refletem sobre a própria morte (Bekkers \& Wiepking, 2007), pelo fato de terem interesse em deixar um legado de caridade para a sociedade (Wiepking, Scaife \& Mcdonald, 2012), por sentimentos de medo (Sargeant \& Woodliffe, 2007), quando ficam tristes ao se depararem com uma situação difícil, ansiosos ou angustiados (Verhaert \& Van Den Poel, 2011), quando buscam perdão (Bekkers \& Wiepking, 2007), e quando carregam sentimento de culpa (Hibbert \& Horne, 1996), afinal, o ato da doação pode gerar no indivíduo a sensação de paz de espírito e melhorar sua auto imagem/estima (Bennett, 2003).

Bennett (2003) ainda reforça que os indivíduos podem doar para fortalecer o ego ou buscar realização pessoal. Ao passo que, para Sargeant (1999), a doação tende a melhorar a autoestima. Indivíduos também doam por almejarem serem respeitados (Andreoni, 1990), quando estão preocupados (Verhaert \& Van Den Poel, 2011), ou por se sentirem obrigados a doar (Hibbert \& Horne, 1996).

Gittell e Tebaldi (2006) identificaram que indivíduos que são voluntários também tendem a doar mais dinheiro por já estarem envolvidos com atos de caridade. Outro motivador de doação é a questão de tradição familiar estudada por Sargeant e Woodliffe (2007), que identificaram que indivíduos que possuem a tradição familiar de doar tendem a doar mais ou tem mais facilidade de se envolver com caridade. Segundo Guy e Patton (1989), o histórico de doação do indivíduo também tende a estar relacionado à doação, pois acredita-se numa repetição e continuidade deste ato.

Assim, como estes motivadores estudados já citados, outras variáveis tendem a motivar indivíduos a doarem, como a lealdade criada junto à organização (Sargeant, 1999), a percepção da necessidade, a identificação com a causa que a organização defende (Bachke, Alfnes \& Wik, 2014) e por ter semelhança entre o doador e o beneficiário que irá receber a doação (Bennett, 2003).

Em suma, para atender ao objetivo deste estudo, foi realizado um levantamento das características pessoais que motivam os doadores a realizarem a doação de dinheiro e/ou bens, e como resultado deste levantamento foram identificados em diversos e diferentes estudos anteriores 58 variáveis, conforme apresentado no Quadro 1. A seguir, na análise dos resultados, foi proposto um agrupamento inicial e de cunho exploratório destas variáveis previamente identificadas.
Quadro 1 - Variáveis Individuais que Motivam a Doação de Dinheiro e/ou Bens.

\begin{tabular}{|c|c|c|}
\hline $\mathbf{N}$ & Variáveis & ção das variáveis \\
\hline 1 & Alegria de Doar & $\begin{array}{l}\text { Alegria de Doar tende a produzir consequências psicológicas } \\
\text { positivas e influencia na doação (Bekkers, 2006; Anik et al., } \\
\text { 2009; Bekkers \& Wiepking, 2010; Bekkers \& Wiepking, } \\
\text { 2011b). }\end{array}$ \\
\hline 2 & Altruísmo & $\begin{array}{l}\text { Indivíduos com sentimentos altruístas tendem a fazer } \\
\text { doações de caridade (Germain et al, 2007; Mittelman \& } \\
\text { Rojas-Méndez, 2013; Bekkers \& Wiepking, 2011b, 2011c). }\end{array}$ \\
\hline 3 & Angústia Pessoal & $\begin{array}{l}\text { Indivíduos tendem a doar quando estão angustiados } \\
\text { (Bennett, 2003; Verhaert \& Van Den Poel, 2011). }\end{array}$ \\
\hline 4 & Ansiedade & $\begin{array}{l}\text { O indivíduo, quando confrontado com necessitados, tende a } \\
\text { sentir ansiedade e querer ajudar por meio de doação } \\
\text { (Verhaert \& Van Den Poel, 2011). }\end{array}$ \\
\hline 5 & Autoestima & $\begin{array}{l}\text { Indivíduos podem ser motivados a doar para melhorar sua } \\
\text { autoestima. (Sargeant, 1999; Grace \& Griffin, 2006) }\end{array}$ \\
\hline 6 & Autoimagem & $\begin{array}{l}\text { Indivíduos tendem a doar para criar uma imagem externa } \\
\text { positiva perante outros indivíduos (Bennett, 2003; Bekkers \& } \\
\text { Wiepking, 2007; Bekkers \& Wiepking, 2011b). }\end{array}$ \\
\hline 7 & $\begin{array}{l}\text { Calma/P } \\
\text { Espirito } \\
\end{array}$ & $\begin{array}{l}\text { O indivíduo pode se sentir mais calmo, "em paz consigo } \\
\text { mesmo", ao efetuar uma doação (Bennett, 2003). }\end{array}$ \\
\hline 8 & Classe Social & $\begin{array}{l}\text { Indivíduos de classe social mais alta tendem a doar menos } \\
\text { devido a estarem menos engajados com problemas sociais } \\
\text { (Sargeant, 1999; Bennett, 2003; Bekkers \& Wiepking, 2007; } \\
\text { Sargeant \& Woodliffe, 2007; Bekkers \& Wiepking, 2011b; } \\
\text { Wiepking \& Breeze, 2012). }\end{array}$ \\
\hline 9 & Compaixão & $\begin{array}{l}\text { Indivíduos com sentimento de compaixão tendem a doar } \\
\text { (Bennett, 2003; Sargeant; Woodliffe, 2007; Verhaert \& Van } \\
\text { Den Poel, 2011). }\end{array}$ \\
\hline 10 & $\begin{array}{l}\text { Sentimento de } \\
\text { Culpa }\end{array}$ & $\begin{array}{l}\text { Indivíduos podem doar para caridade para aliviar sentimento } \\
\text { de culpa (Cunningham, Steinberg \& Grev, 1980; Hibbert \& } \\
\text { Horne, 1996; Bekkers \& Wiepking, 2007; Bekkers \& } \\
\text { Wiepking, 2011b). }\end{array}$ \\
\hline 11 & esejo de ajudar & $\begin{array}{l}\text { Desejo de } \\
\text { pode levar }\end{array}$ \\
\hline 12 & $\begin{array}{l}\text { Desejc } \\
\text { diferer }\end{array}$ & $\begin{array}{l}\text { Indivíduos te } \\
\text { diferença na }\end{array}$ \\
\hline 13 & Ego & $\begin{array}{l}\text { O indivíduo tende a fazer doação a fin } \\
\text { perante a sociedade (Bennett, 2003). }\end{array}$ \\
\hline 14 & Empatia & $\begin{array}{l}\text { Empatia pode evocar comportamento altruísta e } \\
\text { consequentemente influenciar a realização de doações (Lee } \\
\text { \& Chang, 2007; Bekkers \& Wiepking, 2007). }\end{array}$ \\
\hline 15 & Estado civil & $\begin{array}{l}\text { Os indivíduos casados tendem a doar mais que indivíduos } \\
\text { solteiros. (Amato, 1985; Lee \& Chang, 2007; Bekkers, 2010; } \\
\text { Bekkers \& Wiepking, 2011b, 2011d; Wiepking \& Bekkers, } \\
\text { 2012; Wiepking \& Breeze, 2012). }\end{array}$ \\
\hline 16 & star empregado & $\begin{array}{l}\text { Indivíduos empregados têm maior probabilidade de doar do } \\
\text { que os desempregados (Bekkers \& Wiepking, 2007). }\end{array}$ \\
\hline 17 & Gênero & $\begin{array}{l}\text { Mulheres } \\
\text { Grossman } \\
\text { Opoku, 20 }\end{array}$ \\
\hline 18 & Generosidade & $\begin{array}{l}\text { A generosidade do indivíd } \\
\text { processo de doação. (Benne } \\
\text { Poel, 2011; Bekkers \& Wiepk }\end{array}$ \\
\hline 19 & ledonismo & O indivíduo tende a sentir pra \\
\hline 20 & $\begin{array}{l}\text { Repetição de } \\
\text { doação }\end{array}$ & $\begin{array}{l}\text { Um indivíduo que já efetua doação tende a ser mais propenso } \\
\text { a doar novamente no futuro (Guy \& Patton, 1989; Sargeant \& } \\
\text { Woodliffe, 2007). }\end{array}$ \\
\hline 21 & $\begin{array}{l}\text { Estar bem } \\
\text { humorado }\end{array}$ & $\begin{array}{l}\text { O indivíduo com humor positivo tende a doar mais } \\
\text { (Cunningham, Steinberg \& Grev, 1980; Amato, 1985; Guy \& } \\
\text { Patton, 1989; Bekkers \& Wiepking, 2007;). }\end{array}$ \\
\hline 22 & Idade & $\begin{array}{l}\text { Indivíduos idosos tendem a doar mais do que jovens } \\
\text { (Sargeant, 1999; Bennett, 2003; Marx \& Carter, 2014; } \\
\text { Gottesman, et al., 2014; Curtis, Evans \& Cnaan, 2015). }\end{array}$ \\
\hline 23 & $\begin{array}{l}\text { Identificação com } \\
\text { a causa }\end{array}$ & $\begin{array}{l}\text { A doação tende a estar ligada a identificação com a causa } \\
\text { (Bekkers \& Wiepking, 2011a; Bachke, Alfnes \& Wik, 2014). }\end{array}$ \\
\hline 24 & Legado & $\begin{array}{l}\text { Indivíduo doa a fim de deixar um legado de caridade } \\
\text { (Wiepking, Scaife \& McDonald, 2012). }\end{array}$ \\
\hline 25 & ustiç & $\begin{array}{l}\text { fazer doação com o desejo de } \\
\text { ualitário (Bekkers \& Wiepking, }\end{array}$ \\
\hline 26 & to & $\begin{array}{l}\text { unto à organização beneficiária } \\
\text { nutenção da doação (Sargeant, } \\
\text { 2007). }\end{array}$ \\
\hline 27 & Materialismo & $\begin{array}{l}\text { Valores materialistas podem influenciar comportamento de } \\
\text { caridade dos doadores, impulsionando um indivíduo a doar } \\
\text { para certas organizações filantrópicas (Bennett, 2003; Lee \& } \\
\text { Chang, 2007; Mathur, 2013). }\end{array}$ \\
\hline 28 & $\begin{array}{l}\text { Sentiment } \\
\text { medo }\end{array}$ & $\begin{array}{l}\text { podem ser motivados a doar mais quando estão } \\
\text { por alguma situação que envolve sentimentos de } \\
\text { geant \& Woodliffe, 2007; Germain et al., 2007; Lee; } \\
\text { 07). }\end{array}$ \\
\hline 29 & $\begin{array}{l}\text { Morar r } \\
\text { rural e }\end{array}$ & $\begin{array}{l}\text { Os indivíduos que vivem em pequenas cidades e áreas rurais } \\
\text { tendem a estar mais dispostos a ajudar do que os moradores } \\
\text { de cidades grandes (Guy \& Patton, 1989; Bekkers \& } \\
\text { Wiepking, 2006). }\end{array}$ \\
\hline 30 & ível c & $\begin{array}{l}\text { Indivíduos com escolaridade mais alta tendem a fazer } \\
\text { doações mais generosas (Bekkers \& Wiepking, 2006; } \\
\text { Bekkers \& Wiepking, 2010; Choi \& Dinitto, 2012). }\end{array}$ \\
\hline 31 & Ter filhos & $\begin{array}{l}\text { O número de filhos influencia no processo de doação, muitos } \\
\text { indivíduos depois de ter filhos ficam mais sensíveis para fazer } \\
\text { doações para organizações de caridade (Amato, 1985; } \\
\text { Bennett, 2003; Bekkers \& Wiepking, 2007; Osili, Hirt \& } \\
\text { Raghavan, 2011; Wiepking \& Bekkers, 2012). }\end{array}$ \\
\hline 32 & Dever de ajudar & $\begin{array}{l}\text { Indivíduos tendem a fazer doações por se sentirem obrigados } \\
\text { a doar. (Hibbert \& Horne, 1996; Mittelman, Rojas-Méndez, } \\
\text { 2013). }\end{array}$ \\
\hline 33 & rigem étnica & ers; Wiepking, 2007). \\
\hline
\end{tabular}




\begin{tabular}{|c|c|c|}
\hline $\mathbf{N}$ & Variáveis & Definição das variáveis \\
\hline 34 & Pena/piedade & $\begin{array}{l}\text { Indivíduos podem realizar uma doação por sentimentos de } \\
\text { pena ou piedade (Sargeant, 1999; Sargeant \& Woodliff, } \\
\text { 2007). }\end{array}$ \\
\hline 35 & $\begin{array}{l}\text { Pensar sobre a } \\
\text { própria morte }\end{array}$ & $\begin{array}{l}\text { Indivíduos tendem a doar mais quando veem a morte de } \\
\text { perto, quando sentem que precisam de perdão (Bekkers \& } \\
\text { Wiepking, 2007). }\end{array}$ \\
\hline 36 & $\begin{array}{l}\text { Percepção de } \\
\text { necessidade }\end{array}$ & $\begin{array}{l}\text { O indivíduo tem a percepção sobre a necessidade de uma } \\
\text { organização filantrópica receber ajuda (Bachke, Alfnes \& } \\
\text { Wik, 2014). }\end{array}$ \\
\hline 37 & Perdão & $\begin{array}{l}\begin{array}{l}\text { Indivíduos tendem a doar quando precisam de perdão } \\
\text { (Bekkers \& Wiepking, 2007). }\end{array} \\
\end{array}$ \\
\hline 38 & $\begin{array}{l}\text { Possuir casa } \\
\text { própria }\end{array}$ & $\begin{array}{l}\text { Indivíduos que possuem casa própria tendem a doar mais } \\
\text { (Bekkers \& Wiepking, 2006; Bekkers \& Wiepking, 2007; Du et } \\
\text { al., 2014). }\end{array}$ \\
\hline 39 & $\begin{array}{l}\text { Preocupação } \\
\text { com o próximo }\end{array}$ & $\begin{array}{l}\text { Faz doação para ser visto como um indivíduo que se } \\
\text { preocupa com o outro (Verhaert \& Van Den Poel, 2011). }\end{array}$ \\
\hline 40 & Prestígio & $\begin{array}{l}\text { Indivíduo motivado por buscar prestígio público perante suas } \\
\text { contribuições para caridade (Andreoni, 1990; Mittelman \& } \\
\text { Rojas-Méndez, 2013). }\end{array}$ \\
\hline 41 & \begin{tabular}{ll|}
$\begin{array}{l}\text { Profissão de } \\
\text { ajuda }\end{array}$ \\
\end{tabular} & $\begin{array}{l}\text { Indivíduos com uma profissão de ajuda (enfermeiros, } \\
\text { assistentes sociais) tendem a doar mais (Amato, 1985; } \\
\text { Sargeant, 1999; Bekkers, 2010). }\end{array}$ \\
\hline 42 & $\begin{array}{l}\text { Realização } \\
\text { pessoal }\end{array}$ & $\begin{array}{l}\text { Indivíduos tendem a fazer doação para buscar realização } \\
\text { pessoal (Sargeant, 1999; Bennett, 2003). }\end{array}$ \\
\hline 43 & Religião & $\begin{array}{l}\text { Indivíduos que praticam uma religião tendem a ser mais } \\
\text { envolvidos em atos de doação (Bekkers \& Wiepking, 2006; } \\
\text { Bekkers \& Wiepking, 2007; Bekkers \& Wiepking, 2011d; } \\
\text { Casale \& Baumann, 2013). }\end{array}$ \\
\hline 44 & Renda & $\begin{array}{l}\text { Famílias de renda maior tendem a doar valores superiores } \\
\text { em relação a famílias com renda menor (Bekkers \& Wiepking, } \\
\text { 2006; Bekkers \& Wiepking, 2007; Choi \& Dinitto, 2012; } \\
\text { Wiepking \& Bekkers, 2012; Casale \& Baumann, 2013). }\end{array}$ \\
\hline 45 & Reputação social & $\begin{array}{l}\text { A busca pela reputação social pode ser antecedente à } \\
\text { realização de doações (Bekkers \& Wiepking, 2011C; Du, } \\
\text { Qian \& Feng, 2014). }\end{array}$ \\
\hline 46 & \begin{tabular}{|l|}
$\begin{array}{l}\text { Responsabilidade } \\
\text { social }\end{array}$ \\
\end{tabular} & $\begin{array}{l}\text { Indivíduos com senso de responsabilidade social tendem a } \\
\text { doar mais (Schuyt \& Bekkers, 2004; Mathur, 2013). }\end{array}$ \\
\hline 47 & \begin{tabular}{|l|}
$\begin{array}{l}\text { Satisfação } \\
\text { pessoal }\end{array}$ \\
\end{tabular} & $\begin{array}{l}\text { Indivíduos doam para obter satisfação pessoal (Grace \& } \\
\text { Griffin, 2009). }\end{array}$ \\
\hline 48 & $\begin{array}{l}\text { Segurança } \\
\text { financeira }\end{array}$ & $\begin{array}{l}\text { Indivíduos que se sentem financeiramente seguros tendem a } \\
\text { ser potenciais doadores (Wiepking \& Breeze, 2012). }\end{array}$ \\
\hline 49 & $\begin{array}{l}\text { Semelhança } \\
\text { entre doador e } \\
\text { beneficiário } \\
\end{array}$ & $\begin{array}{l}\text { Indivíduos são mais propensos a cumprir com pedidos de } \\
\text { outros indivíduos que são semelhantes a si mesmos } \\
\text { (Bennett, 2003). }\end{array}$ \\
\hline 50 & $\begin{array}{l}\text { Ser reconhecido } \\
\text { como doador }\end{array}$ & $\begin{array}{l}\text { Indivíduos podem doar com o desejo de obter } \\
\text { reconhecimento público (Bekkers \& Schuyt, 2008). }\end{array}$ \\
\hline 51 & Ser Respeitado & $\begin{array}{l}\text { Indivíduos podem fazer doações para se sentirem } \\
\text { respeitados (Andreoni, 1990; Bekkers \& Wiepking, 2006). }\end{array}$ \\
\hline 52 & Ser voluntário & $\begin{array}{l}\text { Sugere que o trabalho voluntário pode contribuir para a } \\
\text { construção de relacionamentos com a organização de } \\
\text { caridade e pode aumentar a probabilidade de doação (Gittell } \\
\text { \& Tebaldi, 2006). }\end{array}$ \\
\hline 53 & $\begin{array}{l}\text { Simpatizar com a } \\
\text { causa }\end{array}$ & $\begin{array}{l}\text { Quando o indivíduo sente simpatia com a causa de caridade } \\
\text { a qual ele se propôs a ajudar (Sargeant, 1999). }\end{array}$ \\
\hline 54 & Status social & $\begin{array}{l}\text { Indivíduos com mais status social tendem a doar mais } \\
\text { (Bekkers \& Wiepking, 2011b). }\end{array}$ \\
\hline 55 & $\begin{array}{l}\text { Tamanho da } \\
\text { cidade do doador }\end{array}$ & $\begin{array}{l}\text { Os indivíduos que residem em cidades maiores tendem a } \\
\text { doar menos (Bekkers \& Wiepking, 2007). }\end{array}$ \\
\hline 56 & Estar saudável & $\begin{array}{l}\text { Pessoas saudáveis doam mais dinheiro/bens (Gottesman, et } \\
\text { al., 2014). }\end{array}$ \\
\hline 57 & Tradição familiar & $\begin{array}{l}\text { O histórico familiar de doação tende a influenciar os } \\
\text { indivíduos no processo de doação, onde filhos de pais que } \\
\text { fazem doação tendem a fazer doações no futuro também } \\
\text { (Sargeant \& Woodliffe, 2007). }\end{array}$ \\
\hline 58 & Tristeza & $\begin{array}{l}\text { Quando confrontado com necessitados, indivíduo pode sentir } \\
\text { tristeza e querer ajudar por meio de doação (Verhaert \& Van } \\
\text { Den Poel, 2011). }\end{array}$ \\
\hline
\end{tabular}

Fonte: Adaptado de Mainardes et al. (2015)

Em resumo, percebe-se que existem muitos aspectos individuais que podem motivar o indivíduo a realizar doações de dinheiro e/ou bens. Neste estudo, foram utilizadas 58 variáveis que caracterizam o doador individual. Estas 58 variáveis pessoais são provenientes de uma larga pesquisa na literatura internacional e foram evidenciadas no contexto brasileiro, em uma extensa pesquisa qualitativa realizada por Mainardes et al. (2015). Assim, percebe-se que agrupar estas variáveis em fatores pode favorecer a identificação de indivíduos mais propensos a efetuar doações de dinheiro/bens, facilitando a captação e retenção de doadores por parte de gestores de organizações de caridade, ressaltando, inclusive, os principais fatores individuais que motivam uma pessoa a realizar uma doação de dinheiro e/ou bens.

\section{Metodologia de Pesquisa}

Para o alcance do objetivo desta pesquisa - o de identificar as características pessoais, e, a seguir, agrupar em fatores pessoais, as motivações dos brasileiros para a realização de doações de dinheiro e/ou bens - foi realizada uma pesquisa exploratória, quantitativa e com corte transversal. A população alvo desta pesquisa foi composta por qualquer indivíduo brasileiro que afirmou efetuar doações de dinheiro e/ou bens para alguma organização de caridade, como, por exemplo, Organizações não-governamentais (ONGs), APAES, hospitais, escolas, creches; ou que faz doações para pessoas carentes. Considerou-se "bens" como qualquer objeto novo ou usado, podendo ser produtos alimentícios, de limpeza e de beleza, roupas, sapatos, utensílios, móveis, entre outros.

Como no Brasil o número de doadores de dinheiro e/ou bens é desconhecido e difícil de ser estimado, a amostra utilizada nesse estudo foi de caráter não probabilística por conveniência e acessibilidade. Considerando que o número de doadores é muito amplo, utilizou-se este tipo de amostragem. Para tanto, a amostra desta pesquisa foi composta por 1.073 indivíduos que são cadastrados como doadores em organizações filantrópicas.

Para a realização da coleta de dados, foi elaborado um questionário com 70 questões. A primeira questão do questionário foi uma questão de controle populacional ("Você realiza doações de dinheiro e/ou bens?"). Foi também inserido um texto explicando qual era o perfil do doador esperado para responder a este questionário. Este procedimento teve como objetivo identificar se o respondente pertencia à população-alvo do estudo e atendia aos requisitos para compor a amostra. Desta forma, caso o respondente afirmasse que não era doador de dinheiro e/ou bens, foi excluído da amostra. Além desta questão, foram utilizadas as 58 variáveis relativas as características pessoais identificadas na literatura como motivadoras da doação de dinheiro e/ou bens (ver Quadro 1, pág. 6). Estas variáveis foram transformadas em afirmações de direcionamento positivo e acompanhadas por uma Escala de Likert de 1 a 5, sendo: (1) Discordo totalmente, (2) Discordo parcialmente, (3) Indiferente (4) Concordo parcialmente e (5) Concordo totalmente. Para cada afirmação, o respondente declarava o seu grau de concordância.

A Escala de Likert de 5 pontos, foi anteriormente utilizada por pesquisadores internacionais (como, por exemplo, Opoku, 2013; Shehu et al., 2016), sendo que o principal motivo da escala reduzida a 5 pontos neste estudo, foi para facilitar a participação dos respondentes, levando em consideração que o questionário era muito extenso. Complementarmente, as últimas 11 questões estavam relacionadas à caracterização da amostra, como a frequência e o tempo de quem já realizava doações de dinheiro e/ou bens, gênero, idade, estado civil, ter filhos, escolaridade, ocupação, renda, localização e tamanho da cidade onde mora. As questões relativas a frequência e o tempo que os doadores já realizavam doações, foram utilizadas para avaliar o perfil dos doadores quanto a sua atuação como doador. Quanto a frequência que realizam doações de dinheiro e/ou bens, 58\% afirmaram que, apesar de realizaram doações frequentes, não tinham uma frequência fixa, 
$18,1 \%$ afirmaram doar mensalmente, $12,6 \%$ anualmente, $8,1 \%$ trimestralmente e 2,2\% semanalmente. Quanto ao tempo que já realizam doações de dinheiro e/ou bens, $28,8 \%$ afirmaram ser doadores há mais de 10 anos, $21 \%$ de 3 a 5 anos, $19,1 \%$ há menos de 1 ano, e 13,8\% de 1 a 2 anos. Todas as respostas foram confidenciais e os respondentes não foram identificados.

O instrumento de coleta de dados foi criado no Google Docs, e foi realizado um pré-teste com 16 indivíduos brasileiros, que afirmaram serem doadores frequentes de dinheiro e/ou bens, no período de 27/04/2015 até 03/05/2015. Esta amostra selecionada para o pré-teste fazia parte do público-alvo da pesquisa e possuía perfil semelhante ao doador genérico de outros países. Neste préteste foram identificados pelos respondentes problemas em relação à interpretação das afirmações propostas. Então, foram realizados os acertos necessários e um novo pré-teste foi aplicado com 10 doadores entre os dias 05/05/2015 até 10/05/2015. Após a confirmação do entendimento do questionário por parte deste segundo grupo, a coleta de dados foi iniciada.

Após verificado que as questões do questionário eram perfeitamente compreendidas pelos respondentes, o questionário elaborado no Google Docs foi disponibilizado por meio eletrônico (e-mail e redes sociais), bem como impresso. Dessa forma, o período de aplicação do questionário foi de 14/05/2015 até 28/07/2015.

Quanto a coleta de dados pelo meio eletrônico (e-mail e redes sociais), o questionário foi divulgado nas redes sociais das organizações de caridade e também foram encaminhados e-mails para as organizações de caridade divulgarem para os seus doadores cadastrados, visto que, buscou-se alcançar exclusivamente doadores cadastrados em organizações filantrópicas. Em relação a coleta de dados presencial, foram impressos 1.850 questionários e entregues em igrejas, hospitais, organizações de apoio as pessoas com deficiência e outras organizações de caridade. Destes, 685 foram devolvidos preenchidos. Dentre estes 685 questionários, 27 foram desconsiderados, pois os respondentes afirmaram não realizar doação de dinheiro e/ou bens.

Quanto à abrangência da localização da amostra, os questionários foram encaminhados para os e-mails organizações de caridade de todo o Brasil, porém, não se identificou nem a organização, nem a localização da organização ou do doador.

Em resumo, foram obtidas 658 respostas por meio de questionários impressos e estes dados foram lançados no Google docs. Os dados coletados diretamente por meio eletrônico foram 415 respostas. Assim, entre os dados coletados por meio dos questionários impressos e o online, foram consideradas válidas 1.073 respostas, e estes foram os dados utilizados nas análises. Os questionários que não estavam adequados, devido aos respondentes terem respondido que não realizavam doação de dinheiro e/ou bens, foram descartados, sendo utilizadas 1.073 respostas válidas.

Ao caracterizar-se a amostra, pôde-se perceber que $66,4 \%$ dos doadores eram do gênero feminino; quanto à idade, $38,2 \%$ possuíam idade entre 26 e 32 anos; quanto ao estado civil, percebeu-se que a maioria dos respondentes era casado $(40,4 \%)$; e $48,37 \%$ dos respondentes afirmaram ter filhos; $42,5 \%$, possui o ensino médio, seguido de $27,3 \%$ com ensino superior. Notou-se que a maioria dos respondentes, 39,5\%, detinha renda entre 1 até 3 salários mínimos. Quanto à ocupação, 70,1\% afirmaram estar empregados e $86,7 \%$ afirmaram morar na zona urbana. Mesmo morando na zona urbana, 46,4\%, afirmaram morar em cidades pequenas. Em relação a frequência da doação, pode-se perceber que $58 \%$ dos doadores não tem uma frequência predeterminada de doação. Por outro lado, aproximadamente $42 \%$ da amostra realiza doações com frequência fixa, sendo que $19,1 \%$, realizam doações mensais de dinheiro e/ou bens. Além disso, 28,8\% afirmou realizar doações há mais de 10 anos. Isto comprova que a amostra pesquisada representa um grupo de doadores comprometidos com a realização de doação de dinheiro e/ou bens.

Desta forma, a caracterização validou a amostra pesquisada, pois percebe-se que a amostra representa a população alvo da pesquisa, apresentando as características gerais médias de doadores de dinheiro e/ou bens, conforme encontrado na literatura existente. Percebe-se que o doador brasileiro, aqui pesquisado, salvo algumas características próprias da população - como população mais jovem, menos escolarizada e com renda mais baixa - mostra-se semelhante ao doador genérico encontrado na literatura internacional existente sobre doação.

Como os dados foram coletados por meio eletrônico e presencialmente, foi realizada o Teste $t$ das duas amostras independentes. Este Teste t comparou as duas amostras (eletrônica e presencial), sendo atendidos os pressupostos da distribuição normal e da igualdade das variâncias. Logo, verificou-se, a partir deste teste, que não ocorreram diferenças estatisticamente significativas entre as amostras utilizadas.

Por fim, para atender ao objetivo desta pesquisa, após coletadas as 1.073 respostas, a análise fatorial foi utilizada para reduzir o número de variáveis em fatores. Tal análise foi utilizada para realizar um agrupamento inicial da variáveis. Desta forma, sistematizar e agrupar estas variáveis favoreceu a identificação de dimensões subjacentes, que tendem a explicar os fatores pessoais que motivam o comportamento do doador individual de dinheiro e/ou bens. O agrupamento das variáveis aconteceu a partir da extração de fatores usando rotação oblíqua não ortogonal, e, para isso, utilizou-se o software SPSS. A seguir, foram realizadas as validades convergente e discriminante.

Como método de análise dos dados, a análise fatorial pode ser exploratória ou confirmatória. Inicialmente, nesta pesquisa, optouse pela análise fatorial exploratória (AFE), que tem como objetivo verificar a relação entre as variáveis sem determinar antecipadamente como os resultados se ajustam (Pestana \& Gageiro, 2008). Por outro lado, a análise fatorial confirmatória (AFC) tem como objetivo comparar resultados obtidos com as dimensões que já constituem a teoria (Pestana \& Gageiro, 2008). Aqui, a AFC foi utilizada para verificar as validades convergente e discriminante dos fatores, bem como para refinar os resultados da AFE. 
Optou-se pela análise fatorial exploratória devido à literatura sobre o comportamento de doação de dinheiro e/ou bens não convergir sobre dimensões já definidas. Foram identificados resultados controversos na literatura. Assim, ao identificar estes resultados divergentes optou-se por não supor antecipadamente dimensões no referencial teórico, mas evidenciar as possíveis dimensões a partir da AFE e validá-las por meio da AFC, onde obteve-se as validades convergente e discriminante.

\section{Análise Fatorial}

Nesta pesquisa, inicialmente, utilizou-se a análise fatorial exploratória, pois segundo Hair et al. (2005), esta análise é indicada quando há um número muito grande de variáveis. Como esta pesquisa identificou 58 variáveis relativas às características pessoais dos doadores, que tendem a motivar a doação de dinheiro e/ou bens, o agrupamento pode facilitar o entendimento de quais são os fatores pessoais dos indivíduos que tendem a favorecer o comportamento de doação.

Antes da realização da análise fatorial exploratória, conforme Pestana e Gageiro (2008), deve-se validar os dados quanto aos outliers, normalidade e dados faltantes/número de não respostas. Quanto aos outliers, a análise foi realizada a partir do gráfico de Box-Plot e do histograma. A normalidade dos dados foi verificada a partir do teste Kolmogorov-Smirnov, e os resultados indicaram uma distribuição não normal. Por fim, em relação aos dados faltantes, os questionários que estavam incompletos, ou seja, com respostas faltantes, foram descartados de imediato e não considerados para compor a amostra, ou seja, das 1.073 respostas consideradas neste estudo, todas estavam com as informações completas.

Ainda Hair et al. (2005) argumentaram que a análise fatorial exploratória também pode ser utilizada quando o tamanho da amostra é cinco vezes maior que número de variáveis analisadas. Como esta pesquisa contou com uma amostra de 1.073 doadores, considerou-se que a amostra também atendeu ao requisito para a realização da análise fatorial exploratória.

A fim de validar a amostra e a utilização da análise fatorial exploratória para o objetivo proposto, inicialmente foi analisada a matriz de correlação entre as variáveis. Foram identificadas 1.275 correlações entre as variáveis utilizadas. Destas, 1.173 foram significativas a $5 \%$, ou seja, $92 \%$ das correlações foram significativas. A seguir, foi utilizado o índice $\mathrm{KMO}$ e o teste de esferacidade de Bartlett. $\mathrm{O}$ índice $\mathrm{KMO}$ apresentou um valor de 0,93, o que sugere a validação do tamanho da amostra e o número de variáveis, pois espera-se, para este tipo de análise, um valor próximo a 1. O teste de esferacidade de Bartlett viabilizou a utilização da análise fatorial exploratória ao apresentar um p-valor menor do que 0,05 . Os resultados descritos são apresentados na tabela 1.

Tabela 1 - Índice KMO, teste de esferacidade Bartlett's e correlações

\begin{tabular}{|l|l|r|}
\hline Kaiser-Meyer-Olkin - Medida de Adequação da Amostra & 0,93 \\
\hline \multirow{3}{*}{ Teste de Esferacidade de Bartletts } & Qui-quadrado aproximado & 18842,72 \\
\cline { 2 - 3 } & Correlações & 1275 (1173 significativas) \\
\cline { 2 - 3 } & P-Valor & 0,00 \\
\hline
\end{tabular}

Após constatada a viabilidade da amostra e da análise fatorial exploratória, as 58 variáveis das características pessoais foram analisadas. A extração foi realizada pela fatorização do eixo principal com rotação oblíqua não ortogonal. Optou-se pela rotação oblíqua não ortogonal, pois evidenciou-se muitas correlações, mesmo que fracas, entre os componentes do mesmo fator. Ao realizar-se a análise fatorial exploratória das 58 variáveis, incialmente foram analisados os valores de comunalidades de cada variável. Nesta análise, o ajustamento final resultou na exclusão de 7 variáveis. As 7 variáveis não foram excluídas de uma vez só. Primeiro foram 2, e foi realizada nova AFE, depois 3 , depois 1 , depois 1. A AFE final foi a quinta rodada de análise. As 7 variáveis que foram excluídas apresentaram comunalidades com valores abaixo de 0,40. As variáveis excluídas foram: alegria de doar, altruísmo, identificação com a causa, religião, responsabilidade social, satisfação pessoal e tristeza. Para validar os resultados foram realizadas mais 3 AFE com $30 \%, 50 \%$ e $70 \%$ da amostra. Os resultados não mostraram diferenças significativas. Sendo assim, ao realizar a AFC para verificação de validade convergente e discriminante, mais 10 variáveis foram excluídas (ego, sentimento de culpa, sentimento de medo, compaixão, generosidade, desejo de fazer a diferença, estar saudável, tamanho da cidade do doador, percepção de necessidade e materialismo). Após estas exclusões, nova AFE foi realizada, sem alteração significativa nos resultados.
Os resultados após todos estes procedimentos são apresentados na Tabela 2.

Após a exclusão destas 17 variáveis, pode-se verificar, por meio da Tabela 2, que foram mantidas 41 variáveis, pois estas apresentaram comunalidades com valores satisfatórios, ou seja, valores acima de 0,50, sendo que comunalidades $\geq 0,40$ também são aceitáveis e neste caso foram mantidas nesta análise. Para complementar a análise das comunalidades, foi utilizada a matriz de correlação anti-imagem. Nesta análise, todas as 41 variáveis apresentaram valores acima de 0,80 , o que indica valores ótimos, não sendo necessário excluir outras variáveis. Em resumo, as 41 características pessoais que foram utilizadas na composição de 10 fatores ( $F 1$ até $F 10)$ são apresentadas na Tabela 2. Os 10 fatores foram validados individualmente por meio de AFEs específicas para cada fator.

A seguir, verificou-se, como mostra a Tabela 2, a carga fatorial exploratória e confirmatória de cada variável. Para Hair et al. (2005), uma carga fatorial acima de 0,30 pode ser considerada aceitável, acima de 0,50 moderadamente importante, e acima de 0,70 muito importante. Também foi verificado a carga fatorial de cada variável em outros fatores, sendo que a carga fatorial maior colocou a variável no fator, desde que as demais cargas fatoriais tivessem uma diferença superior a 0,10, algo encontrado nas 41 variáveis. Assim, por meio da observação da carga fatorial exploratória na 
Tabela 2, pode-se verificar quais são as variáveis mais importantes em cada fator. Os fatores F1, F3, F4, F6, F8 apresentaram algumas variáveis com carga fatorial acima de 0,70 , indicando que estas variáveis são muito importantes para aquele fator. Os demais fatores F2, F5, F7, F9, F10 apresentaram cargas moderadamente importantes, ou seja, todas abaixo de 0,70. Pode-se verificar também, por meio das cargas fatoriais confirmatórias, que todas apresentaram valores acima de 0,50 .

Tabela 2 - Matriz Fatorial de Componentes dos Fatores

\begin{tabular}{|c|c|c|c|c|c|c|c|c|c|}
\hline Fator & Variável & \begin{tabular}{|c|}
$\begin{array}{c}\text { Carga } \\
\text { Fatorial } \\
\text { Explorator } \\
\text { ia }\end{array}$ \\
\end{tabular} & $\begin{array}{c}\begin{array}{c}\text { Comunalida } \\
\text { de }\end{array} \\
\end{array}$ & \begin{tabular}{|c|}
$\begin{array}{c}\text { Carga } \\
\text { Fatorial } \\
\text { Confirmató } \\
\text { ria }\end{array}$ \\
\end{tabular} & KMO & $\begin{array}{c}\text { Qui- } \\
\text { quadrado }\end{array}$ & Df & Bartlett & Correlações \\
\hline \multirow{7}{*}{$\mathrm{F} 1$} & \begin{tabular}{|l|} 
Ser \\
reconhecid \\
$0 \quad$ como \\
doador \\
\end{tabular} & 0,71 & 0,64 & 0,79 & \multirow{7}{*}{0,87} & \multirow{7}{*}{2554,534} & \multirow{7}{*}{21} & \multirow{7}{*}{$\begin{array}{c}0,000 \\
0\end{array} \mid$} & \multirow{7}{*}{$\begin{array}{c}\text { Todas } \\
\text { significativ } \\
\text { as }\end{array}$} \\
\hline & Prestígio & 0,71 & 0,62 & 0,77 & & & & & \\
\hline & \begin{tabular}{|l|}
$\begin{array}{l}\text { Reputação } \\
\text { social }\end{array}$ \\
\end{tabular} & 0,66 & 0,58 & 0,74 & & & & & \\
\hline & $\begin{array}{l}\text { Ser } \\
\text { respeitado }\end{array}$ & 0,65 & 0,62 & 0,76 & & & & & \\
\hline & $\begin{array}{l}\text { Preocupaç } \\
\text { ão com o } \\
\text { próximo }\end{array}$ & 0,56 & 0,55 & 0,67 & & & & & \\
\hline & $\begin{array}{l}\text { Autoimage } \\
\mathrm{m}\end{array}$ & 0,51 & 0,54 & 0,59 & & & & & \\
\hline & \begin{tabular}{|l|}
$\begin{array}{l}\text { Realizção } \\
\text { pessoal }\end{array}$ \\
\end{tabular} & 0,47 & 0,47 & 0,67 & & & & & \\
\hline \multirow{5}{*}{ F2 } & $\begin{array}{l}\text { Origem } \\
\text { étnica }\end{array}$ & 0,65 & 0,6 & 0,74 & \multirow{5}{*}{$0,81 \mid$} & \multirow{5}{*}{$\mid 1367,617$} & \multirow{5}{*}{10} & \multirow{5}{*}{$\begin{array}{c}0,000 \\
0\end{array} \mid$} & \multirow{5}{*}{$\begin{array}{c}\text { Todas } \\
\text { significativ } \\
\text { as }\end{array}$} \\
\hline & $\begin{array}{|ll|}\begin{array}{l}\text { Dever } \\
\text { ajudar }\end{array} & \text { de } \\
\end{array}$ & 0,64 & 0,56 & 0,73 & & & & & \\
\hline & $\begin{array}{l}\text { Nível de } \\
\text { escolaridad } \\
\text { e }\end{array}$ & 0,6 & 0,59 & 0,78 & & & & & \\
\hline & $\begin{array}{l}\text { Morar na } \\
\text { zona rural e } \\
\text { urbana }\end{array}$ & 0,6 & 0,51 & 0,65 & & & & & \\
\hline & Ter filhos & 0,54 & 0,49 & 0,75 & & & & & \\
\hline \multirow{2}{*}{ F3 } & \begin{tabular}{|ll} 
Desejo & de \\
ajudar & \\
\end{tabular} & 0,71 & 0,55 & 0,64 & \multirow{2}{*}{0,83} & \multirow{2}{*}{$\mid 1627,671$} & \multirow{2}{*}{3} & \multirow{2}{*}{0,000} & \multirow{2}{*}{$\begin{array}{c}\text { Todas } \\
\text { significativ } \\
\text { as }\end{array}$} \\
\hline & \begin{tabular}{|l|} 
Hedonismo \\
\end{tabular} & 0,61 & 0,56 & 0,74 & & & & & \\
\hline \multirow{5}{*}{ F4 } & \begin{tabular}{|l} 
Empatia \\
Renda \\
\end{tabular} & $\begin{array}{l}0,59 \\
0,74\end{array}$ & $\begin{array}{l}0,48 \\
0,62\end{array}$ & $\begin{array}{l}0,72 \\
0,74\end{array}$ & \multirow{5}{*}{0,80} & \multirow{5}{*}{1173,133} & \multirow{5}{*}{15} & \multirow{5}{*}{0,000} & \multirow{5}{*}{$\begin{array}{c}1 \text { não } \\
\text { significativ } \\
\text { a }\end{array}$} \\
\hline & $\begin{array}{l}\text { Classe } \\
\text { Social }\end{array}$ & 0,66 & 0,53 & 0,72 & & & & & \\
\hline & $\begin{array}{l}\text { Status } \\
\text { social }\end{array}$ & 0,6 & 0,6 & 0,73 & & & & & \\
\hline & \begin{tabular}{|l|} 
Segurança \\
financeira
\end{tabular} & 0,49 & 0,47 & 0,68 & & & & & \\
\hline & $\begin{array}{l}\begin{array}{l}\text { Profissão } \\
\text { de ajuda }\end{array} \\
\end{array}$ & 0,48 & 0,47 & 0,71 & & & & & \\
\hline
\end{tabular}

\begin{tabular}{|c|c|c|c|c|c|c|c|c|c|}
\hline Fator & Variável & \begin{tabular}{|c|} 
Carga \\
Fatorial \\
Exploratór \\
ia
\end{tabular} & Comunalida & $\begin{array}{c}\text { Carga } \\
\text { Fatorial } \\
\text { Confirmató } \\
\text { ria }\end{array}$ & KMO & $\begin{array}{c}\text { Qui- } \\
\text { quadrado }\end{array}$ & Df & Bartlett & Correlações \\
\hline & $\begin{array}{l}\text { Possuir } \\
\text { casa } \\
\text { própria }\end{array}$ & 0,46 & 0,52 & 0,72 & & & & & \\
\hline \multirow{4}{*}{ F5 } & $\begin{array}{l}\text { Simpatizar } \\
\text { com a } \\
\text { causa }\end{array}$ & 0,65 & 0,55 & 0,75 & \multirow{4}{*}{0,83} & \multirow{4}{*}{1680,212} & \multirow{4}{*}{6} & \multirow{4}{*}{0,000} & \multirow{4}{*}{$\begin{array}{c}\text { Todas } \\
\text { significativ } \\
\text { as }\end{array}$} \\
\hline & $\begin{array}{l}\text { Ser } \\
\text { voluntário }\end{array}$ & 0,64 & 0,55 & 0,71 & & & & & \\
\hline & $\begin{array}{l}\text { Tradição } \\
\text { familiar }\end{array}$ & 0,53 & 0,48 & 0,72 & & & & & \\
\hline & $\begin{array}{l}\text { Semelhanç } \\
\text { a entre } \\
\text { doador e } \\
\text { beneficiário }\end{array}$ & 0,48 & 0,49 & 0,71 & & & & & \\
\hline \multirow{4}{*}{ F6 } & Autoestima & 0,77 & 0,67 & 0,79 & \multirow{4}{*}{0,82} & \multirow{4}{*}{1526,957} & \multirow{4}{*}{6} & \multirow{4}{*}{0,000} & \multirow{4}{*}{$\begin{array}{l}\text { Todas } \\
\text { significativ } \\
\text { as }\end{array}$} \\
\hline & Ansiedade & 0,66 & 0,54 & 0,72 & & & & & \\
\hline & $\begin{array}{l}\text { Angústia } \\
\text { Pessoal }\end{array}$ & 0,62 & 0,56 & 0,68 & & & & & \\
\hline & $\begin{array}{l}\text { Calma/Paz } \\
\text { de Espirito }\end{array}$ & 0,5 & 0,45 & 0,68 & & & & & \\
\hline \multirow[b]{3}{*}{ F7 } & $\begin{array}{l}\text { Pena/pieda } \\
\text { de }\end{array}$ & 0,53 & 0,54 & 0,7 & \multirow[b]{3}{*}{0,83} & \multirow[b]{3}{*}{1548,625} & \multirow[b]{3}{*}{3} & \multirow[b]{3}{*}{0,000} & \multirow{3}{*}{$\begin{array}{c}\text { Todas } \\
\text { significativ } \\
\text { as }\end{array}$} \\
\hline & Perdão & 0,52 & 0,54 & 0,8 & & & & & \\
\hline & $\begin{array}{l}\text { Pensar } \\
\text { sobre } \\
\text { própria } \\
\text { morte } \\
\end{array}$ & 0,47 & 0,56 & 0,84 & & & & & \\
\hline \multirow{3}{*}{ F8 } & $\begin{array}{l}\text { Lealdade à } \\
\text { organizaçã } \\
0 \\
\text { beneficiária }\end{array}$ & 0,71 & 0,61 & 0,8 & \multirow{3}{*}{$-0,83$} & \multirow{3}{*}{$|1688,81|$} & \multirow{3}{*}{3} & \multirow{3}{*}{0,000} & \multirow{3}{*}{$\begin{array}{c}\text { Todas } \\
\text { significativ } \\
\text { as }\end{array}$} \\
\hline & \begin{tabular}{|l|} 
Legado de \\
caridade
\end{tabular} & 0,59 & 0,54 & 0,71 & & & & & \\
\hline & $\begin{array}{l}\text { Justiça } \\
\text { social }\end{array}$ & 0,58 & 0,57 & 0,74 & & & & & \\
\hline \multirow{3}{*}{ F9 } & Estado civil & 0,66 & 0,6 & 0,76 & \multirow{3}{*}{0,85} & \multirow{3}{*}{1866,34} & \multirow{3}{*}{3} & \multirow{3}{*}{0,000} & \multirow{3}{*}{$\begin{array}{c}\text { Todas } \\
\text { significativ } \\
\text { as }\end{array}$} \\
\hline & \begin{tabular}{|l|} 
Estar \\
empregado
\end{tabular} & 0,55 & 0,56 & 0,7 & & & & & \\
\hline & Gênero & 0,47 & 0,47 & 0,8 & & & & & \\
\hline \multirow{3}{*}{$\mathrm{F} 10$} & \begin{tabular}{|l|} 
Estar bem \\
humorado
\end{tabular} & 0,64 & 0,53 & 0,75 & \multirow{3}{*}{0,82} & \multirow{3}{*}{1361,359} & & & \\
\hline & $\begin{array}{l}\text { Repetição } \\
\text { de doação }\end{array}$ & 0,61 & 0,57 & 0,77 & & & 3 & 0,000 & $\begin{array}{c}\text { significativ } \\
\text { as }\end{array}$ \\
\hline & Idade & 0,46 & 0,44 & 0,74 & & & & & \\
\hline
\end{tabular}

Fonte: Dados da pesquisa.

Desta forma, as variáveis com as cargas fatoriais mais altas em cada fator foram utilizadas para auxiliar a nomeação dos fatores. Com base na literatura e na carga fatorial das variáveis, foram criados os nomes dos 10 fatores, conforme apresentado no Quadro 2.

Quadro 2 - Fatores Pessoais que Motivam a Doação de Dinheiro e/ou Bens.

\begin{tabular}{|l|l|l|l|l|}
\hline FATOR & NOME DO FATOR & FATOR & NOME DO FATOR \\
\hline F1 & Conformidade Social & F6 & Benefícios Psicológicos \\
\hline F2 & Aspectos Sociodemográficos & F7 & Auto Reflexão \\
\hline F3 & Necessidade e Prazer em Ajudar & F8 & Contribuição à Sociedade \\
\hline F4 & Aspectos Econômicos & F9 & Situação pessoal \\
\hline F5 & Comprometimento com o Próximo & F10 & Humor e Hábito \\
\hline
\end{tabular}

\section{Fonte: Elaboração própria}

Após nomeados os fatores, a Tabela 3 apresentou os 10 fatores, e os respectivos percentuais da variância, variância acumulada, a confiabilidade do fator por meio do valor do Alfa de Cronbach, e os valores da AVE (Average Variance Extracted) e CR (Composite Reliability).

Tabela 3 - Total da Variância Explicada

\begin{tabular}{|c|c|c|c|c|c|c|}
\hline \multirow[b]{2}{*}{ FATOR } & \multicolumn{3}{|c|}{$\begin{array}{l}\text { SOMAS DA EXTRAÇÃO DE } \\
\text { CARGAS AO QUADRADO }\end{array}$} & \multirow{2}{*}{$\begin{array}{l}\text { Alfa de } \\
\text { Cronbach }\end{array}$} & \multirow[b]{2}{*}{ AVE } & \multirow[b]{2}{*}{ CR } \\
\hline & Total & $\begin{array}{c}\% \\
\text { Variância }\end{array}$ & $\begin{array}{c}\text { Variância } \\
\text { Acumulada } \\
\%\end{array}$ & & & \\
\hline F1 - Conformidade Social & 4,56 & 8,94 & 8,94 & 0,85 & 0,51 & 0,88 \\
\hline $\begin{array}{l}\text { F2 - } \quad \text { Aspectos } \\
\text { Sociodemográficos }\end{array}$ & 3,61 & 7,09 & 16,02 & 0,80 & 0,54 & 0,85 \\
\hline $\begin{array}{l}\text { F3 - Necessidade e Prazer } \\
\text { em ajudar }\end{array}$ & 3,29 & 6,45 & 22,48 & 0,75 & 0,50 & 0,80 \\
\hline F4 - Aspectos Econômicos & 3,10 & 6,08 & 28,56 & 0,7 & 0,51 & 0,84 \\
\hline F5 - Comprometimento com & 2,66 & 5,21 & 33,77 & 0,71 & 0,52 & 0,81 \\
\hline
\end{tabular}

\begin{tabular}{|c|c|c|c|c|c|c|}
\hline \multirow[b]{2}{*}{ FATOR } & \multicolumn{3}{|c|}{$\begin{array}{l}\text { SOMAS DA EXTRAÇĀO DE } \\
\text { CARGAS AO QUADRADO }\end{array}$} & \multirow{2}{*}{$\begin{array}{l}\text { Alfa de } \\
\text { Cronbach }\end{array}$} & \multirow[b]{2}{*}{ AVE } & \multirow[b]{2}{*}{$\mathrm{CR}$} \\
\hline & Total & $\begin{array}{c}\% \\
\text { Variância }\end{array}$ & $\begin{array}{c}\text { Variância } \\
\text { Acumulada } \\
\%\end{array}$ & & & \\
\hline \multicolumn{7}{|l|}{ o próximo } \\
\hline F6 - Benefícios Psicológicos & 2,55 & 4,99 & 38,77 & 0,69 & 0,52 & 0,81 \\
\hline F7 - Auto Reflexão & 1,95 & 3,82 & 42,58 & 0,64 & 0,61 & 0,82 \\
\hline $\begin{array}{l}\text { F8 - Contribuição à } \\
\text { Sociedade }\end{array}$ & 1,94 & 3,81 & 46,39 & 0,61 & 0,56 & 0,79 \\
\hline F9 - Situação Pessoal & 1,92 & 3,77 & 50,17 & 0,62 & 0,57 & 0,80 \\
\hline F10 - Humor e Hábito & 1,74 & 3,41 & 53,57 & 0,62 & 0,57 & 0,80 \\
\hline
\end{tabular}
Fonte: Dados da pesquisa.

Observa-se, por meio da Tabela 3, que a solução fatorial composta pelos 10 fatores apresentou uma combinação lógica das variáveis e explicou $53,57 \%$ da variância total. A Tabela 3 apresentou ainda os valores da validade convergente, onde os valores da AVE foram maior que 0,5 , e o CR maior que 0,7 . Desta forma, a validade convergente é satisfatória neste estudo. Pode-se 
verificar, por meio da Tabela 4, que a validade discriminante também foi satisfatória, uma vez que as correlações entre os fatores foi inferior à raiz quadrada da AVE (diagonal principal na tabela 4).

Tabela 4 - Validade Discriminante

\begin{tabular}{|c|c|c|c|c|c|c|c|c|c|c|}
\hline Fator & F1 & F2 & F3 & F4 & F5 & F6 & F7 & F8 & F9 & F10 \\
\hline F1 - Conformidade Social & $\begin{array}{c}0,7 \\
2\end{array}$ & & & & & & & & & \\
\hline F2 - Aspectos Sociodemográficos & $\begin{array}{c}0,5 \\
2\end{array}$ & $\begin{array}{c}0,7 \\
3\end{array}$ & & & & & & & & \\
\hline $\begin{array}{l}\text { F3 - Necessidade e Prazer em } \\
\text { ajudar }\end{array}$ & $\begin{array}{c}0,0 \\
8\end{array}$ & $\begin{array}{c}0,0 \\
2\end{array}$ & $\begin{array}{c}0,7 \\
1\end{array}$ & & & & & & & \\
\hline F4 - Aspectos Econômicos & $\begin{array}{c}0,5 \\
7\end{array}$ & $\begin{array}{c}0,4 \\
9\end{array}$ & $\begin{array}{c}0,2 \\
0\end{array}$ & $\begin{array}{c}0,7 \\
1\end{array}$ & & & & & & \\
\hline $\begin{array}{l}\text { F5 - Comprometimento com } \\
\text { o próximo }\end{array}$ & $\begin{array}{c}0,4 \\
9\end{array}$ & $\begin{array}{c}0,3 \\
1\end{array}$ & \begin{tabular}{|c|}
0,3 \\
5
\end{tabular} & $\begin{array}{c}0,5 \\
4\end{array}$ & $\begin{array}{c}0,7 \\
2\end{array}$ & & & & & \\
\hline F6 - Benefícios Psicológicos & $\begin{array}{c}0,4 \\
6\end{array}$ & $\begin{array}{c}0,3 \\
9\end{array}$ & $\begin{array}{c}0,2 \\
3\end{array}$ & $\begin{array}{c}0,3 \\
3\end{array}$ & $\begin{array}{c}0,3 \\
2\end{array}$ & $\begin{array}{c}0,7 \\
2\end{array}$ & & & & \\
\hline F7 - Auto Reflexão & $\begin{array}{c}0,5 \\
5\end{array}$ & $\begin{array}{c}0,5 \\
0\end{array}$ & $\begin{array}{c}0,1 \\
3\end{array}$ & $\begin{array}{c}0,4 \\
1\end{array}$ & $\begin{array}{c}0,3 \\
6\end{array}$ & $\begin{array}{l}0,3 \\
7\end{array}$ & $\begin{array}{c}0,7 \\
8\end{array}$ & & & \\
\hline F8 - Contribuição à Sociedade & $\begin{array}{c}0,3 \\
8\end{array}$ & $\begin{array}{c}0,3 \\
5 \\
\end{array}$ & \begin{tabular}{|c|}
0,3 \\
3 \\
\end{tabular} & $\begin{array}{c}0,3 \\
8\end{array}$ & $\begin{array}{c}0,4 \\
6 \\
\end{array}$ & $\begin{array}{c}0,3 \\
7\end{array}$ & $\begin{array}{c}0,3 \\
0\end{array}$ & $\begin{array}{c}0,7 \\
5 \\
\end{array}$ & & \\
\hline F9 - Situação Pessoal & $\begin{array}{c}0,2 \\
4\end{array}$ & $\begin{array}{c}0,2 \\
1 \\
\end{array}$ & \begin{tabular}{|c|}
0,4 \\
1 \\
\end{tabular} & \begin{tabular}{|c|}
0,2 \\
6 \\
\end{tabular} & \begin{tabular}{|c|}
0,3 \\
1
\end{tabular} & \begin{tabular}{|c|}
0,2 \\
5 \\
\end{tabular} & $\begin{array}{c}0,2 \\
1 \\
\end{array}$ & \begin{tabular}{|c|}
0,3 \\
3 \\
\end{tabular} & $\begin{array}{c}0,7 \\
6\end{array}$ & \\
\hline F10 - Humor e Hábito & \begin{tabular}{|c|}
0,3 \\
3
\end{tabular} & \begin{tabular}{|c|}
0,4 \\
3 \\
\end{tabular} & $\begin{array}{c}0,2 \\
7\end{array}$ & $\begin{array}{c}0,4 \\
4\end{array}$ & \begin{tabular}{|c|}
0,3 \\
9
\end{tabular} & $\begin{array}{c}0,3 \\
3\end{array}$ & $\begin{array}{c}0,3 \\
1\end{array}$ & $\begin{array}{c}0,4 \\
3\end{array}$ & $\begin{array}{c}0,2 \\
1\end{array}$ & $\begin{array}{c}0,7 \\
6\end{array}$ \\
\hline
\end{tabular}

Fonte: Dados da pesquisa.

Ao analisar individualmente cada fator, pode-se perceber o que o primeiro fator (F1) "Conformidade Social" foi composto por 7 variáveis. Entende-se que este fator tende a ser o que mais influencia o comportamento de doação de dinheiro e/ou bens, pois foi o responsável por explicar a maior parte da variância do total, $8,94 \%$. Isso sugere, conforme identificado anteriormente por Andreoni (1990), Bennett (2003), Bekkers e Schuyt (2008), Bekkers e Wiepking (2011c), Mittelman e Rojas-Méndez (2013) e Du, Qian e Feng (2014), que dentre as características pessoais que motivam os doadores a realizarem doações, parece existir a necessidade de o indivíduo querer melhorar sua própria percepção como pessoa, seja por intermédio do reconhecimento e prestígio perante a sociedade, bem como conseguir melhorar sua reputação social e ser respeitado.

Já Hibbert e Horne (1996), Sargeant (1999), Bennett (2003) e Bekkers e Wiepking (2007, 2011b) identificaram que os indivíduos, também podem, por meio das doações, buscar a realização pessoal e demonstrar preocupação para com o próximo, e todas estas variáveis também podem contribuir para melhorar a percepção pessoal do doador e motivar a doação. Por meio deste fator, podese observar a importância que os doadores pesquisados dão para o seu próprio comportamento pessoal.

O segundo fator (F2) foi nomeado como "Aspectos Sociodemográficos" e foi composto por 5 variáveis. Constatou-se que os aspectos sociodemográficos dos doadores, como a origem étnica do doador, o local de moradia (zona rural e/ou urbana), ter filhos e o nível de escolaridade podem influenciar no comportamento do doador de dinheiro e/ou bens. Estas variáveis foram estudadas anteriormente por Amato (1985), Bennett (2003), Wiepking (2006), Bekkers e Wiepking (2006, 2007), Osili, Hirt, Raghavan (2011). Estima-se também que indivíduos podem ser motivados a realizar doação de dinheiro e/ou bens por outro aspecto sociodemográficos, como sentir-se no dever de ajudar, sendo esta variável analisada anteriormente por Hibbert e Horne (1996) e Mittelman e Rojas Méndez (2013). Este fator apresentou uma variância de 7,09\%, assim, tende a ser o segundo fator que mais influencia o comportamento de doação.

O terceiro fator (F3), denominado "Necessidade e Prazer em Ajudar", agrupou 3 variáveis, sendo que estas obtiveram um poder explicativo de 6,45\%. Este fator pode ser explicado pelo desejo do doador querer ajudar, e foi identificado anteriormente nos estudos Fong (2007) e Michel e Rieunier (2012). Sugere-se ainda que as variáveis empatia e hedonismo, que compõem o fator 3 , já estudadas por Bennett (2003), Lee e Chang (2007) e Bekkers e Wiepking (2007), podem motivar a doação de dinheiro e/ou bens, uma vez que os doadores visualizam que outras pessoas ou organizações necessitam de ajuda. Desta forma, para Guy e Patton (1989), cabe aos profissionais de marketing terem em mente que a motivação básica do doador não é especificamente ajudar a organização, mas ajudar a quem está passando por necessidades. Assim, este agrupamento apontou que a necessidade e o prazer em ajudar pode levar os indivíduos a realizarem tais doações.

O quarto fator (F4) "Aspectos Econômicos” reuniu 6 variáveis. Este fator corrobora com os estudos de Sargeant (1999), Bennett (2003), Bekkers e Wiepking (2006, 2007, 2011b, 2012), Sargeant e Woodliffe, (2007), Wiepking e Breeze (2012), Choi e Dinitto (2012), Casele e Baumann (2013), que identificaram que, aspectos econômicos como a renda, a classe social e o status social, tendem a influenciar no ato da doação. Percebe-se, ainda, que os doadores que possuem segurança financeira tendem a serem doadores com mais facilidade, bem como aqueles que já possuem uma casa própria e profissão de ajuda, como anteriormente identificado por Amato (1985), Sargeant (1999), Bekkers e Wiepking (2006, 2007, 2010), Wiepking e Breeze (2012), Du et al. (2014). Este fator obteve uma variância total de $6,08 \%$, o que demonstra que os aspectos econômicos do indivíduo tende também a influenciar no processo de doação.

O "Comprometimento com o Próximo" foi o quinto fator (F5) e contou com 4 variáveis. Este fator engloba as características pessoais, que podem levá-lo ao comprometimento com o próximo. Conforme estudado anteriormente, os doadores, ao simpatizarem e/ou se identificarem com a causa (Sargeant, 1999; Bekkers \& Wiepking, 2011a; Bachke, Alfnes \& Wik, 2014) e/ou verificarem alguma semelhança com o beneficiário da doação (Bennett, 2003) podem comprometer-se com o ato da doação. Da mesma forma, os doadores que vem de famílias com tradição de realizar doações e trabalhos voluntários, também tendem a se comprometer com mais facilidade em atos de doação, corroborando com os estudos de Gittell e Tebaldi (2006) e Sargeant e Woodliffe (2007). Este fator obteve uma variância total de 5,21\% e sugere-se que as variáveis que compõem o fator comprometimento com o próximo tendem a motivar o ato da doação.

O sexto fator (F6) "Benefícios Psicológicos" foi composto por 4 variáveis. O resultado do agrupamento das variáveis deste fator suportou os achados de Sargeant (1999), Bennett (2003), Grace e Griffin (2006) e Verhaert e Van Den Poel (2011). Estes autores 
sugerem que os doadores realizam doações para melhorarem a sua autoestima ou reduzirem sentimentos de ansiedade e angústia, o que consequentemente pode gerar nos doadores a sensação de sentir-se mais calmo e em paz consigo mesmo. Este fator obteve poder explicativo da variância de 4,99\%, levando a entender que os benefícios psicológicos gerados pela doação tendem a motivar os doadores a doar.

O sétimo fator (F7), relativo à "Auto Reflexão", agrupou 3 variáveis, sendo elas, o sentimento de pena/piedade, perdão e pensar sobre a própria morte, identificadas anteriormente nos estudos de Sargeant (1999), Sargeant e Woodliff (2007), Bekkers e Wiepking (2007). Estas variáveis sugerem que os doadores podem sentir pena ou piedade ao perceberem que uma organização de caridade ou indivíduo está passando por necessidade, levando-os a realização de doações. Os doadores também podem envolver-se mais em atos de doação e ajuda ao próximo quando veem a morte de perto ou quando precisam de perdão. Este fator apresentou uma variância total de $3,82 \%$.

O oitavo fator (F8) foi relativo à "Contribuição à Sociedade", que agrupou 3 variáveis. Este fator corroborou com os estudos de Sargeant (1999), Sargeant e Woodliffe (2007), Bekkers e Wiepking (2011b) e Wiepking, Scaife, e McDonald (2012) e agrupou variáveis que estão vinculadas à contribuição das pessoas à sociedade. Estão ligados à lealdade que o próprio doador criou junto à organização beneficiária, assim como o interesse em deixar para a sociedade um legado de caridade, além da vontade de criar um mundo mais justo e/ou igualitário. Este fator apresentou uma variância total de $3,81 \%$, e, por meio deste resultado, estima-se que os valores pessoais do doador podem motivar a doação de dinheiro e/ou bens.

A "Situação Pessoal" foi o nono fator (F9), que agrupou 3 variáveis: o estado civil, estar empregado e o gênero. Este agrupamento sugere que o estado civil e o gênero tendem a influenciar no processo de doação. Conforme identificado anteriormente de que indivíduos casados (Amato, 1985; Lee \& Chang, 2007; Bekkers, 2010; Bekkers \& Wiepking, 2011b, 2011d; Wiepking \& Breeze, 2012) e as Mulheres (Eckel \& Grossman, 1998; Wiepking, 2009; Wiepking \& Bekkers, 2012; Opoku, 2013) tendem a ser mais propensos a realizar doações. Estima-se ainda que, conforme o estudo de Bekkers e Wiepking (2007), indivíduos empregados também estão mais propícios ao ato da doação dos que os desempregados. O agrupamento destas três variáveis pessoais, explicou $3,77 \%$ da variância total e tendem a contribuir para a explicação do comportamento de doação de dinheiro e/ou bens.

O décimo fator (F10), "Humor e Hábito", foi composto por 3 variáveis. Este agrupamento foi composto pelas variáveis, estar bem humorado, repetição de doação e idade. Verifica-se que os doadores bem humorados possuem uma propensão maior de ajudar por meio de doações (Cunningham, Steinberg \& Grev, 1980; Guy \& Patton, 1989; Bekkers \& Wiepking, 2007), assim como os indivíduos que já realizaram doações anteriormente tendem a ter mais propensão em repetir atos de doação (Sargeant \& Woodliffe,
2007). A idade do indivíduo também tende a influenciar na propensão em ajudar, ou seja, quanto mais idade, maior a disposição em ajudar (Sargeant, 1999). Complementarmente, como as variáveis deste fator apresentaram uma variância total explicado de $3,41 \%$, considera-se que a propensão de ajudar do indivíduo favorece a doação de dinheiro e/ou bens.

Constatou-se por meio dos valores resultantes das contribuições das variâncias, que não houve uma diferença muito grande entre os fatores, uma vez que o fator principal explicou apenas $8,94 \%$ da variância total. Isso sugere que diversas características pessoais motivam a doação de dinheiro e/ou bens e que podem variar entre os doadores, o que pode sugerir possíveis clusters entre os doadores. Pode-se também verificar pela estrutura de fatores desenvolvida que não há um fator preponderante que motiva doadores em geral a efetuarem doações de dinheiro e/ou bens.

Por fim, analisou-se na Tabela 3, a confiabilidade dos fatores gerados por meio do Alfa de Cronbach, que, segundo Hair et al. (2005), representam a confiabilidade dos fatores, ou seja, o grau de intensidade da associação das variáveis. Percebe-se que os fatores conformidade social (F1) e aspectos sociodemográficos (F2) obtiveram um valor alfa de 0,85 e 0,80 , respectivamente, considerada uma confiabilidade "muito boa". Isso evidencia que as variáveis que compõem cada fator, ao serem combinados, podem mensurar de forma coerente os fatores conformidade social e aspectos sociodemográficos. Os fatores F3, F4, F5 obtiveram alfas considerados "bons" e que indicam que a combinação dos fatores também pode ser considerada válida. Os fatores F6, F7, F8, F9 e F10 obtiveram valores moderados para o alfa. Desta forma, constatou-se que as variáveis de todos os fatores foram agrupadas de forma coerente e tendem a explicar as características pessoais que motivam a doação de dinheiro e/ou bens.

Em síntese, pode-se perceber que, com a solução apresentada por meio de 41 variáveis identificadas na literatura, encontrou-se 10 fatores que tendem a explicar as características pessoais que motivam a doação de dinheiro e/ou bens. Assim, estes fatores e suas correspondentes variáveis podem auxiliar os gestores das organizações de caridade a analisar de forma sistematizada quais fatores pessoais podem influenciar o doador, para que tal doador decida pelo ato da doação de dinheiro e/ou bens.

\section{Conclusões e Implicações}

O objetivo desta pesquisa foi definir os fatores pessoais que motivam a doação de dinheiro e/ou bens. Após realizada a análise dos dados, pôde-se concluir que 41 características pessoais que estavam dispersas na literatura foram agrupadas e agora podem ser definidas por meio dos 10 fatores, o que facilita a compreensão das variáveis e do tema estudado, a doação, e, especificamente, o comportamento do doador de dinheiro e/ou bens. Verificou-se nos resultados que alguns fatores apresentaram uma maior contribuição para explicar o comportamento do doador brasileiro, como, por exemplo, a Conformidade Social e Aspectos sociodemográficos. Os 
resultados também evidenciam que os 10 fatores contribuem de forma diferente ao explicar o comportamento do doador.

Para a teoria, esta pesquisa corroborou com os estudos relativos ao comportamento do consumidor, especificamente o comportamento do doador brasileiro de dinheiro e/ou bens, levando-se em consideração a existência de poucos estudos sobre este perfil de doador no contexto brasileiro. Outra contribuição deste trabalho foi a identificação das 58 características pessoais que motivam a doação de dinheiro e/ou bens e o agrupamento destas variáveis em fatores, favorecendo o entendimento do que mobiliza os indivíduos ao ato da doação, por meio dos 10 fatores. Este agrupamento pode ser considerado inédito na literatura científica brasileira.

$\mathrm{Na}$ prática, espera-se que os resultados desta pesquisa possam ser utilizados pelos gestores das organizações de caridade e/ou por pessoas que captam recursos junto a doadores individuais, como um conhecimento útil para melhorar suas estratégias de gestão, de captação e manutenção dos recursos financeiros e humanos. Pode-se também, a partir da identificação dos fatores pessoais dos doadores, criar estratégias para torná-los doadores de dinheiro e/ou bens mais generosos, frequentes e de longo prazo. Considera-se que a partir desta pesquisa, na qual foi realizada a sistematização das variáveis, os gestores não necessitarão analisar as 58 variáveis isoladamente para compreender as características pessoais que motivam a doação, mas visualizá-las a partir dos 10 fatores.

Como limitação desta pesquisa, verifica-se a realização da AFC com a mesma amostra da AFE. Deste modo, sugere-se que pesquisa futuras realizem a análise fatorial confirmatória com outras amostras, confirmando as validades convergente e discriminante dos fatores encontrados aqui, refinando os achados. Outra limitação a ser considerada é que foram identificadas na literatura 58 características pessoais que motivam a doação de dinheiro e/ou bens, presumindo-se que compreender o comportamento do doador é algo complexo, e que podem haver outras características pessoais que explicam o comportamento de doação de dinheiro e/ou bens e que não foram identificadas e inseridas nesta pesquisa. Desta forma, sugere-se que pesquisas futuras possam incluir (ou mesmo excluir) variáveis e identificar novos fatores. Além disso, como a amostragem foi não probabilística por conveniência e acessibilidade, os resultados deste estudo não são generalizáveis.

Outra limitação está relacionada com as 58 variáveis, que foram provenientes da literatura estrangeira, não tendo sido identificado na literatura brasileira pesquisas suficientes sobre o comportamento do doador de dinheiro e/ou bens. Ainda, esta pesquisa limitou-se a estudar somente os fatores internos, mas reconhece-se que os doadores também podem receber influências externas. Assim, pesquisas futuras podem agrupar os fatores internos e externos, ou podem buscar identificar e agrupar em fatores variados motivadores externos.

Outra sugestão de pesquisa futura é a realização de uma análise de clusters, visto que pelos resultados obtidos pela análise de variância, não obteve-se um fator que demonstrasse muita importância comparada aos demais fatores (pequenas diferenças na variância explicada), e isso pode ter ocorrido pela heterogeneidade da amostra pesquisada. Sugere-se ainda que, em pesquisas futuras, possam ser realizadas análises de associações entre os fatores e o próprio ato da doação. Por fim, como a amostra foi heterogênea, sugere-se que em pesquisas futuras possam ser analisados segmentos específicos de doadores, como, por exemplo, doadores religiosos, para causas internacionais, ou apenas de dinheiro e ou de bens.

Pode-se também estudar grupos específicos de doadores, a partir de suas características sociodemográficas, como a idade, a renda, o estado civil, a escolaridade, a profissão, a raça, a classe social, o lugar de moradia do doador, variáveis estas já identificadas anteriormente na literatura, como características sociodemográficas, que explicam comportamentos distintos entre os doadores (Guy \& Patton, 1989; Sargeant, 1999; Bennett, 2003; Bekkers \& Wiepking, 2006, 2007; Choi \& Dinitto, 2012; Casale \& Baumann, 2013; Marx \& Carter, 2014; Gottesman, Et Al., 2014; Curtis, Evans \& Cnaan, 2015).

\section{Referências}

Agostinho, D., \& Paço, A. (2012). Analysis of the motivations, generativity and demographics of the food bank volunteer. International Journal of Nonprofit and Voluntary Sector Marketing, 17(3), 249-261.

Amato, P. R. (1985). An investigation of planned helping behavior. Journal of Research in Personality, 19(2), 232-252.

Andreoni, J. (1990). Impure altruism and donations to public goods: A theory of warm-glow giving. The economic journal, 100(401), 464-477.

Anik, L., Aknin, L. B., Norton, M. I., \& Dunn, E. W. (2009). Feeling good about giving: The benefits (and costs) of self-interested charitable behavior. Harvard Business School Marketing Unit Working Paper, (10-012).

Bachke, M. E., Alfnes, F., \& Wik, M. (2014). Eliciting donor preferences. VOLUNTAS: International Journal of Voluntary and Nonprofit Organizations, 25(2), 465-486.

Barcellos, R. F. (2014). O Comportamento dos doadores brasileiros: proposição e teste de um modelo explicativo. (Dissertação Mestrado em Administração) - Fundação Instituto Capixaba de Pesquisa em Contabilidade, Economia e Finanças - FUCAPE, Vitória, Espirito Santo, Brasil.

Bekkers, R., \& Wiepking, P. (2006). To give or not to give, that is the question: How methodology is destiny in Dutch giving data. Nonprofit and Voluntary Sector Quarterly, 35(3), 533-540.

Bekkers, R., \& Wiepking, P. (2007, October). Understanding philanthropy: A review of 50 years of theories and research. In 35th Annual Conference of the Association for Research on Nonprofit and Voluntary Action, Chicago.

Bekkers, R., \& Schuyt, T. (2008). And who is your neighbor? Explaining denominational differences in charitable giving and volunteering in the Netherlands. Review of Religious Research, 74-96.

Bekkers, R. (2010). Who gives what and when? A scenario study of intentions to give time and money. Social Science Research, 39(3), 369-381.

Bekkers, R., \& Wiepking, P. (2011a). Accuracy of self-reports on donations to charitable organizations. Quality \& Quantity, 45(6), 1369-1383.

Bekkers, R., \& Wiepking, P. (2011b). A literature review of empirical studies of philanthropy: Eight mechanisms that drive charitable giving. Nonprofit and Voluntary Sector Quarterly. 40(5), 924-973.

Bekkers, R., \& Wiepking, P. (2011c). Testing mechanisms for philanthropic behaviour. International Journal of Nonprofit and Voluntary Sector Marketing, 16(4), 291-297.

Bekkers, R., \& Wiepking, P. (2011d). Who gives? A literature review of predictors of charitable giving part one: religion, education, age and socialisation. Voluntary Sector Review, 2(3), 337-365.

Bennett, R. (2003). Factors underlying the inclination to donate to particular types of charity. International Journal of Nonprofit and Voluntary Sector Marketing, 8(1), 12-29.

Borgonovi, F. (2008). Divided we stand, united we fall: Religious pluralism, giving, and volunteering. American Sociological Review, 73(1), 105-128.

Casale, D., \& Baumann, A. (2013). Who gives to international causes? A sociodemographic analysis of US donors. Nonprofit and Voluntary Sector Quarterly. DOI:10.1177/0899764013507141.

Charities Aid Foundation. World giving index 2012: A global view of giving trends.

Disponível 
<http://www.cafonline.org/PDF/WorldGivingIndex2012WEB.pdf>. Acesso em: 08 abr. 2015.

Charities Aid Foundation. World giving index 2014: A global view of giving trends. Disponível em: <http://www.cafonline.org/PDF/WorldGivinglndex2012WEB.pdf>. Acesso em: 08 abr. 2015.

Choi, N. G., \& DiNitto, D. M. (2012). Predictors of time volunteering, religious giving, and secular giving: Implications for nonprofit organizations. organizations. Journal of Sociology and Social Welfare, 39 (3),
93 .

Cronin-Gilmore, J., Bates, M., \& Brown, D. (2014). Brand awareness: A community perception of a nonprofit organisation. Journal of Brand Strategy,3(2), 155-168.

Cunningham, M. R., Steinberg, J., \& Grev, R. (1980). Wanting to and having to help: Separate motivations for positive mood and guilt-induced helping. Journal of Personality and Social Psychology, 38(2), 181-192.

Curtis, D. W., Evans, V., \& Cnaan, R. A. (2015). Charitable practices of Latterday Saints. Nonprofit and Voluntary Sector Quarterly, 44 (1), 146-162.

Du, L., Qian, L., \& Feng, Y. (2014). Influences of altruistic motivation, shared vision, and perceived accessibility on microcharity behavior. Social Behavio and Personality: an international journal, 42(10), 1639-1650.

Du, X., Jian, W., Du, Y., Feng, W., \& Zeng, Q. (2014). Religion, the nature of ultimate owner, and corporate philanthropic giving: Evidence from China. Journal of Business Ethics, 123(2), 235-256.

Eckel, C. C., \& Grossman, P. J. (1998). Are women less selfish than men?: Evidence from dictator experiments. The economic journal, 108(448), 726 735.

Fong, C. M. (2007). Evidence from an experiment on charity to welfare recipients: Reciprocity, altruism and the empathic responsiveness hypothesis. The Economic Journal, 117(522), 1008-1024.

Gazley, B., \& Abner, G. (2014). Evaluating a Product Donation Program: Challenges for Charitable Capacity. Nonprofit Management and Leadership,24(3), 337-355.

Germain, M., Glynn, S. A., Schreiber, G. B., Gelinas, S., King, M., Jones, M., ... \& Tu, Y. (2007). Determinants of return behavior: a comparison of current and lapsed donors. Transfusion, 47(10), 1862-1870.

Gittell, R., \& Tebaldi, E. (2006). Charitable giving: Factors influencing giving in US states. Nonprofit and Voluntary Sector Quarterly, 35(4), 721-736.

Gottesman, W. L., Reagan, A. J., \& Dodds, P. S. (2014). Collective Philanthropy: Describing and Modeling the Ecology of Giving. PloS one, 9(7), 1-20.

Grace, D., \& Griffin, D. (2006). Exploring conspicuousness in the context of donation behaviour. International Journal of Nonprofit and Voluntary Sector Marketing, 11(2), 147-154.

Grace, D., \& Griffin, D. (2009). Conspicuous donation behaviour: scale development and validation. Journal of consumer behaviour, 8(1), 14-25.

Guy, B. S., \& Patton, W. E. (1989). The marketing of altruistic causes: understanding why people help. Journal of Consumer Marketing, 6(1), 19-30.

Hair Jr, J. F., Babin, B., Money, A. H., \& Samouel, P. (2005). Fundamentos de métodos de pesquisa em administração.

Hibbert, S., \& Horne, S. (1996). Giving to charity: questioning the donor decision process. Journal of Consumer Marketing, 13(2), 4-13.

Kim, Namin. (2014). Advertising strategies for charities: Promoting consumers' donation of time versus money. International Journal of Advertising, 33(4), 707-724.

Lee, S., Winterich, K. P., \& Ross, W. T. (2014). I'm moral, but I won't help you: The distinct roles of empathy and justice in donations. Journal of Consumer Research, 41(3), 678-696.

Lee, Y. K., \& Chang, C. T. (2007). Who gives what to charity? Characteristics affecting donation behavior. Social Behavior and Personality: an international journal, 35(9), 1173-1180.

Mainardes, E. W., Laurett, R., Degasperi, N., Lasso, S. (2015, Junho). Personal characteristics and external motivadors as antecedents to the act of money and/or goods donation. Anais do $14^{\text {th }}$ International Congress of the
Internacional Association on Public and Nonprofit Marketing, IANPM, Vitória, Espírito Santo, Brasil.

Marx, J. D., \& Carter, V. B. (2014). Factors Influencing US Charitable Giving during the Great Recession: Implications for Nonprofit Administration. Administrative Sciences, 4(3), 350-372.

Mathur, A. (2013). Materialism and charitable giving: Can they co-exist? Journal of Consumer Behaviour, 12(3), 149-158.

Merchant, A., Ford, J. B., \& Sargeant, A. (2010). 'Don't forget to say thank you': The effect of an acknowledgement on donor relationships. Journal of Marketing Management, 26(7-8), 593-611.

Michel, G., \& Rieunier, S. (2012). Nonprofit brand image and typicality influences on charitable giving. Journal of Business Research, 65(5), 701 707.

Mittelman, R., \& Rojas-Méndez, J. I. (2013). Exploring Consumer's Needs and Motivations in Online Social Lending for Development. Journal of Nonprofit \& Public Sector Marketing, 25(4), 309-333.

Opoku, R. A. (2013). Examining the motivational factors behind charitable giving among young people in a prominent Islamic country. International Journal of Nonprofit and Voluntary Sector Marketing, 18(3), 172-186.

Osili, U. O., Hirt, D. E., \& Raghavan, S. (2011). Charitable giving inside and outside the workplace: The role of individual and firm characteristics. International Journal of Nonprofit and Voluntary Sector Marketing, 16(4), 393 408.

Ottoni-Wilhelm, M. (2010). Giving to organizations that help people in need: Differences across denominational identities. Journal for the Scientific Study of Religion, 49(3), 389-412.

Pestana, M. H., \& Gageiro, J. N. (2008). Análise de dados para ciências sociais: a complementaridade do SPSS. (5a Edicão) Lisboa. Edições Sílabo.

Sargeant, A. (1999). Charitable giving: Towards a model of donor behaviour. Journal of Marketing Management, 15(4), 215-238.

Sargeant, A., \& Woodliffe, L. (2007). Gift giving: an interdisciplinary review. International Journal of Nonprofit and Voluntary Sector Marketing, 12(4), 275 307.

Shehu, E., Becker, J. U., Langmaack, A. C., \& Clement, M. (2016). The brand personality of nonprofit organizations and the influence of monetary incentives. Journal of Business Ethics, 138(3), 589-600.

Teixeira, R. K. C., Gonçalves, T. B., \& Silva, J. A. C. D. (2012). Is the intention to donate organs influenced by the public's understanding of brain death?.Revista Brasileira de terapia intensiva, 24(3), 258-262.

Verhaert, G. A., \& Van den Poel, D. (2011). Empathy as added value in predicting donation behavior. Journal of Business Research, 64(12), 12881295.

Whitehead III, G. I. (2014). Correlates of Volunteerism and Charitable Giving in the 50 United States. North American Journal of Psychology, 16(3), 531.

Wiepking, P., \& Bekkers, R. (2012). Who gives? A literature review of predictors of charitable giving. Part Two: Gender, family composition and income. Voluntary Sector Review, 3(2), 217-245.

Wiepking, P., \& Breeze, B. (2012). Feeling poor, acting stingy: The effect of money perceptions on charitable giving. International Journal of Nonprofit and Voluntary Sector Marketing, 17(1), 13-24.

Wiepking, P., Scaife, W., \& McDonald, K. (2012). Motives and barriers to bequest giving. Journal of Consumer Behaviour, 11(1), 56-66.

Winterich, K. P., \& Zhang, Y. (2014). Accepting inequality deters responsibility: How power distance decreases charitable behavior. Journal of Consumer Research, 41(2), 274-293.

Wymer Jr, W. W., \& Samu, S. (2002). Volunteer service as symbolic consumption: Gender and occupational differences in volunteering. Journal of Marketing Management, 18(9-10), 971-989.

Yörük, B. K. (2013). The impact of charitable subsidies on religious giving and attendance: Evidence from panel data. Review of Economics and Statistics,95(5), 1708-1721.

Zago, A., Silveira, M. F. D., \& Dumith, S. C. (2010). Blood donation prevalence and associated factors in Pelotas, Southern Brazil. Revista de Saúde Pública,44(1), 112-120.

Agradecimentos: Esta pesquisa foi financiada pelo Conselho Nacional de Desenvolvimento Científico e Tecnológico (CNPq), projeto número 303669/2015-2, e pela Fundação de Amparo à Pesquisa do Espírito Santo (FAPES) 